Research Paper

\title{
Numerical investigation of roof heating impacts on thermal comfort and air quality in urban canyons
}

\author{
Seyyed Hossein Hosseini ${ }^{\text {a,* }}$, Parisa Ghobadi ${ }^{b}$, Toran Ahmadi ${ }^{b}$, John Kaiser Calautit $^{c}$ \\ a Department of Chemical Engineering, Faculty of Engineering, Ilam University, Ilam 69315-516, Iran \\ ${ }^{\mathrm{b}}$ Department of Architecture, Faculty of Engineering, Ilam University, Ilam 69315-516, Iran \\ ${ }^{\mathrm{C}}$ Department of Architecture and Built Environment, University of Nottingham, Nottingham NG7 2RD, UK
}
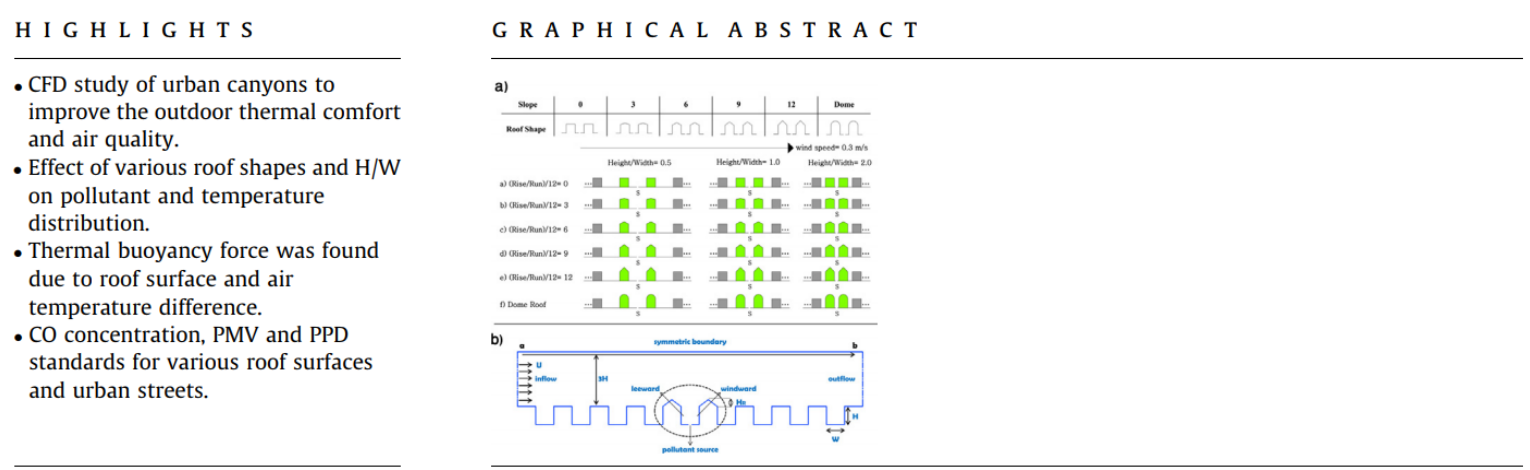

\begin{abstract}
Impacts of thermal and buoyancy forces on the thermal comfort and air quality in urban canyons with different $\mathrm{H} / \mathrm{W}$ ratios and rise/run ratio of rooftops are studied. 18 isothermal and non-isothermal models are studied by CFD modelling validated with experimental data from the literature. Based on the results, thermal buoyancy is observed to be effective in improving human comfort in the urban canyon. The temperature difference between roof surface and air increases the speed of air and contaminant transport in urban canyons. While the increase in height and tilt of structures around urban areas have shown to reduce thermal buoyancy. In broad canyons such as $\mathrm{H} / \mathrm{W}=0.5$, an increase in height and slope of the roof causes the thermal comfort of leeward, windward, and central regions to move away from the neutral comfort conditions. In regular canyons, $\mathrm{H} / \mathrm{W}=1$, the thermal comfort reduces for highly slanted roofs models. Domed roof leads to the lack of thermal comfort in upper levels of passages in leeward, windward, and central regions. In deep canyons, $\mathrm{H} / \mathrm{W}=2$, high level of thermal comfort appears only for flat roofs. With an increase in roof height (rise/run), Predicted Mean Vote PMV index moves away from the comfort range. By increasing $\mathrm{H} / \mathrm{W}$ ratio, roof height, wind comfort, and air quality inside regular and deep urban canyons, it was observed that the thermal buoyancy force leads to the reduction in thermal comfort.
\end{abstract}

Keywords: street canyon configuration, roof surface heating, thermal comfort, air quality, CFD. 


\section{Introduction}

More than 50 percent of the world's population lives in developed urban areas, which continues to grow due to population growth and consequent rapid urbanization [1]. Expansion of cities and development of massive urban structures, along with increased exploitation of natural surfaces, are important factors in causing climatic changes in urban areas [2]. Many urban and suburban areas experience higher temperature compared to rural areas, which is due to the formation of heat trapping and occurrence of heat island phenomenon [3]. Urban heat island (UHI) is one of the most important atmospheric phenomena in urban areas, which is mostly caused by the reduction of evaporation, reflection coefficient, thermal diffusion, heat capacity and human heat generation [4]. Urban heat island (UHI) is a temperature difference between the surface and atmosphere of rural and urban areas that becomes more apparent at night and under smooth and quiet climatic conditions [5]. The Intensity of heat island is mainly determined by the thermal balance of the area and thus, daily changes and short-term weather conditions [3]. Accordingly, UHI is defined as the temperature difference between the urbanized areas and their surroundings, i.e. $\left(\mathrm{T}_{\text {urban }}-\mathrm{T}_{\text {rural }}\right)[5]$.

Replacing natural areas with surfaces absorbing solar radiation, such as roofs, sidewalks, streets and so on, increases the air temperature in urban areas by $10-20{ }^{\circ} \mathrm{C}$ [6]. Heat and energy imbalance creates a temperature difference in urban and suburban areas, which in addition to climatic changes, is associated to a reduction in the quality of the living environment, increase in energy consumption, increase in smog and air pollutants, and eventually even increase in the risk of mortality.

There is no doubt that improving human comfort and consequently the loss of energy in the building is one of the challenges involved in modern societies. "Human comfort" is attained once the environment provides the proper conditions to avoid unpleasant feeling based on the weather predictions. Outdoor human comfort in an urban climate may be affected by a wide range of weather and human factors. It can be found that temperature, clothing, wind speed, sunlight, humidity and evaporative cooling contribute to a satisfactory environmental condition [7]. In this regard, a variety of methods has been proposed to optimize the situation based on technology development; while studying urban comfort is a matter that has been forgotten and requires further study in order to improve comfort and energy efficiency. Outdoor spaces have a significant contribution to the prosperity and quality of life and human comfort. These spaces are affected by various aspects such as population and urban development, physical layout, anthropogenic sources, climatic conditions, geographical location and so on [5]. Most studies conducted in this field show that among the above-mentioned variables, geometric and climatic factors have a significant impact in improving human comfort in urban areas [8]. Simultaneous study of the impact of climatic and physical conditions is essential in analyzing an urban microclimate in order to assess environmental factors. Physical parameters, in turn, affect environmental and climatic variables; for example, the urban environment has undergone changes such as reduction of wind speed and solar radiation reserves due to an improper geometry of its structures [9].

As mentioned earlier, different studies on thermal comfort and improvement of air quality in urban pathways have become a focal point in environmental studies because of the complex interaction of different and sometimes uncontrollable variables. However, previous studies [10] conducted in this area lack the required information for evaluating different aspects and relevant variables affecting the improvement of thermal comfort and air quality in street canyons. Therefore, the significance of this study is evaluating different physical and environmental parameters using CFD model in order to improve human comfort and air quality in urban canyons. On the other hand, most comprehensive studies have 
focused on aerodynamic parameters of urban canyons and outdoor human comfort has not been investigated yet.

In developed urban areas, structures close to each other are always considered as a place for thermal mass trapping that increases air pollution. The effect of geometry and physical layout on the air velocity distribution in dense urban areas is very significant; therefore, the configuration of streets and buildings can cause significant changes in the pattern and velocity of air flow in urban canyons. In the past two decades, many scholars [11] have studied the effects of geometry and configuration of buildings on airflow patterns and behaviors in urban canyons. Air flow patterns and dispersion of pollutants, as well as heat transfer in urban canyons, are largely formed by the configuration of buildings around the canyon; thus, the mentioned parameters are mainly determined by aspect ratio ${ }^{1}$ of the canyon, the symmetry of urban structures, shapes of the buildings' roofs [12,13], speed and direction of the wind [14], and atmospheric instability [15]. In addition to the physical layout of the canyon, roof structure and geometry also significantly affect the flow pattern, isotherm temperature, and turbulent kinetic energy intensity in the pathways [16]. Many studies showed that air flow patterns and turbulence intensity generated in the back of the buildings are different for roofs of various buildings. With the increase of vortices in the wind flow, the speed of wind flow and dispersion of pollutants in the area is reduced. Slanted roofs create the greatest turbulence, while turbulence in the leeward area covers less area for buildings with domed roofs [17]. In this regard, Huang et al. [18] investigated slanted and wedge-shaped roofs for buildings around the urban canyon. Yassin et al. [19] investigated the effect of street intersection on air quality and pollutant dispersion in an urban canyon. Ibid investigated height and shape of buildings' roof using a twodimensional [20] and three-dimensional [12] turbulent model. Xie et al. [21] studied the effect of street geometry on air flow and dispersion of pollutants. Koutsourakis et al. [22] demonstrated that different structures of canyons and different velocities of air flow affect the transport and dispersion of pollution sources. Calculation of velocity and pollutant concentrations in the previous studies showed that the pattern of vortices, air flow, and pollutants' dispersion are greatly dependent on the geometry and physical layout of urban canyons.

Kovar-Panskus et al. [23] conducted the wind tunnel to investigate the effect of solar-induced wallheating on the pattern of air flow within an urban street canyon and found that upwind heating is associated to the generation of a very weak street-bottom secondary stream. Kim and Baik [8] also studied heat and aerodynamic transfer due to street-bottom and building roof thermal effects.

In the presence of street-bottom heating, as heating intensity increases, the mean kinetic energy increases in the spanwise street canyon formed by the upwind and downwind buildings, but decreases in the lower region of the streamwise street canyon. The increase in momentum due to buoyancy force intensifies mechanically induced flow in the spanwise street canyon and the vorticity in the spanwise street canyon is strengthened. The increase of temperature is not large because the relatively cold above-roof-level air comes into the spanwise street canyon. In the presence of both street-bottom and building roof heating, the mean kinetic energy is rather decreased in the spanwise street canyon [8].

Xie et al. [24] also investigated the thermal effect of building facades with different H/W ratios for flat roofs. The results showed that the thermal effect of heating surfaces plays an important role in the structure of the air flow and pollutant concentrations. Heating surfaces in deep and vast canyons increase accumulation of pollutants in the leeward area, while the opposite occurs in regular canyons. Thermal comfort, energy saving and inhaled air quality in indoor and outdoor are strongly affected by the flow interaction in the micro-environment around the occupants.

\footnotetext{
${ }^{1}$ Aspect ratio is defined as the ratio between the average height $(\mathrm{H})$ of the canyon walls and the canyon width $(\mathrm{W}) ; \mathrm{H} / \mathrm{W}$.
} 
Over the past decade, evaluation of thermal comfort has attracted the attention of many engineers, planners, and urban planners because of the critical state of environmental crisis, climatic changes and increase in heat stress in urban areas. In addition to improving environmental issues, thermal comfort in open spaces affects the physical and mental health of citizens. "Thermal comfort" is the condition of mind that expresses satisfaction with the thermal environment and is defined by subjective evaluation described in ANSI/ASHRAE Standard 55. ASHRAE standard establishes the ranges of environmental conditions that are acceptable to achieve thermal comfort for human [25]. Outdoor spaces are important to sustainable cities because they accommodate pedestrian traffic and outdoor activities, and contribute greatly to urban livability and vitality. In the global context of climate change, outdoor spaces that provide a pleasurable thermal comfort experience for pedestrians effectively improve the quality of urban living. The influence of thermal comfort on outdoor activities is a complex issue comprising both climatic and behavioral aspects; however, current investigations lack a general framework for assessment [26]. Also, the wind comfort can address questions regarding the human life quality in the urban areas.

However, relatively few studies have been done on thermal comfort in open spaces [27,28]; on the other hand, most studies have focused on buildings. It is noteworthy that Ali-Toudert and Mayer [29] studied the effects of aspect ratio and orientation of an urban street canyon on outdoor thermal comfort in hot and dry climate. The work was restricted to the canyons with just flat roof structure. They didn't study thermal impacts of roof surface on the flow patterns of urban streets. In addition, they used ENVI-MET software, which is dedicated to the study of microclimate changes in urban environments. Therefore, the present study focuses on roof heating and shapes to improve the thermal comfort in open urban areas for the first time.

Use of cool roofs to reflect solar radiation and green surfaces is very promising in reducing the heatisland phenomenon [30]. Using high-albedo urban cold surfaces and planting trees and vegetation are low-cost measures that reduce the temperature of towns and cooling energy demand of buildings and prevent the formation of smoke and increase in pollutant concentrations [31]. Some studies on cool roofs have shown that the temperature difference of roof surface and the air is approximately $10^{\circ} \mathrm{C}$ in highalbedo roofs [32].

Studies using urban airshed model in Los Angeles showed that using cool roofs directly reduces the annual cost of air-conditioning by $20 \%$ and also reduces the emission of greenhouse gasses by $10 \%$ [1]. Many researchers such as Akbari [33], Akbari et al. [34], and Kolokotsa et al. [35] have studied the effect of cool roofs on reducing energy consumption, greenhouse gas emission, and human comfort improvement in buildings in different climates. The results clearly showed that roofs' cooling potential is so remarkable and can significantly help reduce the temperature of the urban environment and consequently reduce energy consumption, greenhouse gas emissions, and improve human comfort at building levels.

According to the literature, most studies conducted on this issue have investigated the roof shape in isothermal conditions and just some of them have discussed the buoyancy and aerodynamic forces simultaneously, which were used just for flat roofs. In these studies, thermal effects are investigated for interior surfaces of canyons (the upwind surface, leeward surface, and land surface) and, except for a few studies investigating the thermal effect of flat roofs [36,37], enough studies have not been conducted in this regard.

The present study aims to evaluate the effect of thermal and mechanical buoyancy forces with different $\mathrm{H} / \mathrm{W}$ ratios and rise/run ratios as well as shapes of rooftops in urban canyons by CFD tool to improve thermal comfort in urban streets. In addition, the roofs have been simulated in cases of isothermal and non-isothermal. Accordingly, 18 models are investigated using K-epsilon RNG turbulence model within a 
two-dimensional framework. It is noteworthy that the results obtained from experimental wind tunnel study conducted by Uehara et al. [38] and the numerical results of Xie et al. [24] are used for validation of the model used in this study.

\section{Methodology}

The use of laboratory and analytical techniques is impractical due to the complexity of some systems studied in reality, the current technical developments in many cases, and frequency of variables. In this respect, numerical methods provide a fair and beneficial mechanism to overcome uncertainty without creating any restrictions on the system. Recently, computational fluid dynamics (CFD) has emerged as an effective tool for predicting various phenomena related to the fluids, such as flow pattern, heat, and mass transfer [39]. Since the topics studied in this research are from various fields such as heat transfer, pollution transportation and aerodynamic issues, the use of CFD software, as the most efficient and most reliable research tool, is beneficial. The configuration of the physical model, description of boundary conditions and mathematical models are explained, subsequently.

\subsection{Configuration of the physical model and mesh}

The physical structure of the models studied in this paper is designed in a two-dimensional environment consisting of 10 buildings and 9 urban canyons. The roofs are slanted and dome-shaped with rise/run ratios of equal to $0,3,6,9,12$ and canyons with $\mathrm{H} / \mathrm{W}$ ratios of $0.5,1,2$. In all models, building height and width are $\mathrm{H}=1 \mathrm{~m}$ and $\mathrm{W}=1 \mathrm{~m}$, respectively. The height of the roofs of the upwind and downwind buildings in the center of the model are $\mathrm{H}_{\mathrm{R}}=0,0.125,0.25,0.375,0.5 \mathrm{~m}$. Also slope $=\frac{\mathrm{run} / \mathrm{rise}}{12}$.

In accordance with the layout standards provided in the handbook on the architectural design for domeshaped roofs, the proper height of the dome is equal to half of its crater [40]. The model used in this study follows the layout standard and height of the dome-shaped roof is $5 \mathrm{~m}$. Wind direction is perpendicular to the street $(\mathrm{X}$-direction $=1, \mathrm{Y}$-direction $=0$ ) and buildings are equally located at regular intervals in both upstream and downstream of the central street. The coordinate system is measured at $X$ positive in the direction of the wind and at $\mathrm{Z}$ positive in the upward direction. In this study, 6 different roof shapes are simulated with $3 \mathrm{H} / \mathrm{W}$ ratios and both isothermal and non-isothermal temperature conditions referring to Fig. 1(a).

Meshing is performed using Gambit 2.4.6 software. Near the walls, small boundary layer mesh has been used. The wall Y + test was conducted to verify the accuracy of the mesh near the walls and the results (Y $+<5$ ) showed that the area of laminar sublayer is also covered. A two-dimensional computational domain is used in the wind flow direction perpendicular to the street canyon. The non-uniform triangular grid structure is chosen as it is closer to the building and ground, and then it is expanded further away. The grid independency was investigated by comparing the simulation results for four grid sizes of $(35 \times 195,45 \times 380,65 \times 760$ and $105 \times 1520)$ in terms of dimensionless horizontal velocity along the street canyon height. Grid independency was reached with a mesh size of $45 \times 380$, which is not shown here for the sake of brevity.

\subsection{Boundary conditions and description of the problem:}

The velocity inlet and outflow of boundary conditions were used to simulate the airflow in the computational domain. The temperature difference between air and the urban surfaces is dependent on various climate conditions. Oke used the maximum temperature difference between air and the urban surfaces structures (facades of buildings, the ground, etc.) in the range of $10-15{ }^{\circ} \mathrm{C}$ for different climates of large cities [41]. In the Asimakopoulos et al. research, the temperature difference of $10{ }^{\circ} \mathrm{C}$ was reported for the developed urban areas [42]. Noted that in several studies the temperature difference between air and the urban surfaces was estimated in the range of $10-20{ }^{\circ} \mathrm{C}[5,43,44]$. Therefore, based on 
the above-mentioned studies, and according to the analysis of meteorological data for Tehran with hot and dry climate, the temperature difference of $10{ }^{\circ} \mathrm{C}$ was selected for the simulations. Based on the studies of Xie et al. [16,24] and Yassin [20] in the inlet section, an initial constant speed of $0.3 \mathrm{~m} / \mathrm{s}$, low turbulence intensity (5\%), and the air temperature of $298.15 \mathrm{~K}$ was used. The temperature of surfaces (ground, the windward, and leeward regions) was considered as $308.15 \mathrm{~K}$. The Reynolds number is 13100, which confirms the turbulent flow. ${ }^{2}$

The non-slip wall boundary condition is used for solid surfaces, including the ground and body of the building [16,20,23]. The turbulent intensity in the inlet fluid boundary condition is calculated to be $5 \%$. Physical and thermal properties of different surfaces such as the ground, the windward region, the leeward region, and roof are also selected according to [45]:

\subsection{Theoretical model}

A suitable turbulence model for numerical analysis is required to get an accurate simulation. Several studies in the field of simulation of temperature patterns, air flow and pollutant concentrations in urban canyons showed that the standard and RNG k-epsilon turbulence models provided solutions with acceptable accuracy [46]. Renormalized Group (RNG) k-epsilon turbulent model is used for modeling turbulent motions and transport. Modeling constants for RNG k-epsilon turbulent model are as follows:

$C_{\mu}=0.0845, C_{\varepsilon 1}=1.42, C_{\varepsilon 2}=1.68, \sigma_{k}, \sigma_{\varepsilon}, C_{\varepsilon 3}=$ Analytical formula

Simulation of models in this research was performed by Ansys Fluent 15.0 software in a 2D framework, in steady-state and pressure-based conditions. Note that in the previous CFD simulation of regular canyons [20,24], a 2D framework was also employed. In addition, Baik et al. [47] studied the reactive pollutant dispersion in an urban street canyon by CFD at 2D and 3D geometries. They achieved the same results using these frameworks.

In this Paper, Two-dimensional flow and dispersion of gaseous pollutants were analyzed using standard $\mathrm{k}-\varepsilon$ turbulence model, which was numerically solved based on Reynolds-Averaged Navier-Stokes (RANS) equations. Also, the vehicular exhaust was simulated in the form of a continuous ground-level line source placed along the centerline of the street. Carbon monoxide (CO) was used as the hypothetical vehicular exhaust because of its relatively inert chemical behaviors and prolonged resident time in the atmospheric boundary layer $[24,48]$.

The turbulence caused by buoyancy is considered as a thermal effect in urban canyons. When heat is added to a fluid and the fluid density varies with temperature (fluid density is a function of temperature), a flotation flow is formed due to gravity on the changes in density. Modeling combined thermal effects, turbulence and natural convection in steady state is performed using Boussinesq model. The model is used in the analysis of fluid flows that are affected by buoyant force, where the difference in temperature of surface and fluid is not large [49]. The inlet fluid (air) has a density of 1.184 (density = $1.184 \mathrm{~kg} /$ $\mathrm{m} 3)$ and a coefficient of thermal expansion of .003 $(\beta=0.0031 / \mathrm{K})$.

The governing equations are found in FLUENT documentation [48] and to summarize the paper they have been not shown here. Similar to previous studies [20,24,38,47], wind flow speed profile is defined in the form of a constant velocity, $\mathrm{U}$, along the inflow border.

${ }^{2} R e=\frac{\rho \cdot U \cdot D_{H}}{\mu}=\frac{1.184 \times 0.3 \times 1}{1.8 \times 10^{-5}} \approx 13100$, where $D_{H}=\frac{4 A}{P}=\frac{2 a b}{a+b}$ 
The governing equations are discretized using finite volume method and a SIMPLE algorithm is used for solving equations. Least squares cell based is the method used for computing the gradient in previous equations, the discretization scheme used for the pressure equation is PRESTO and the discretization scheme that is used for solving momentum, TKE, TDR, energy, and pollutant concentration equations is second order upwind.

Under-Relaxation factors for solving equations are $0.7,1,0.3,0.8$ and 0.9 for pressure, density, momentum, turbulence kinetic energy, and energy, respectively. A convergence criterion of $10^{-6}$ for each scaled residual component has been specified for the relative error between two successive iterations. The thermal comfort modeling and assessment method in this study were also previously used for estimating

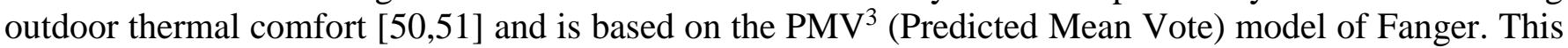
model has been expanded and developed according to environmental (temperature, radiant temperature, humidity and air velocity) and personal (activities and dressing) parameters in vitro conditions; the range of acceptable thermal comfort in the Fanger model is $-0.5 \leq \mathrm{PMV} \leq 0.5$ and $\mathrm{PPD}^{4}<10 \%$ [52]. Using PMVFanger index to study thermal comfort in open spaces (urban environment) has also been approved [26,50,51]. In this study, PMV-Fanger model and psychometrics charts were used to study thermal comfort in three leeward, windward, and central areas for presented models.

According to the previous works [53], in the current study, humidity has not been considered in the CFD model. On the other hand, to estimate PMV, the average moisture content in the hot and dry climate of Tehran has been used for the warm seasons. The influence of humidity on the CFD results and PMV is proposed for the future researches.

Conditions in urban canyon environments for investigating thermal sensation and percentage of dissatisfaction are: mean radiant temperature of $25^{\circ} \mathrm{C}$, humidity of $40 \%$, the metabolic rate of 1.4 met $^{5}$, and clothing insulation level of $0.5 \mathrm{clo}^{6}$ in the summer. This model was developed based on principles of heat balance and experimental data collected under steady-state weather conditions [54].

\subsection{Model Validation:}

In order to ensure that the model used in the current work provides accurate predictions, it was validated against experimental and numerical data of previous studies. Thus, the results obtained from the model of rise/run $=0$ (Flat roof) in the $\mathrm{H} / \mathrm{W}=1$ (regular canyon) were validated with wind tunnel experiments and existing simulation. By comparing the data, a minimal difference was observed between numerical and experimental results. Research models have been validated using the results of wind tunnel atmospheric emissions operated by Uehara et al [38] that were conducted in Japan's National Institute for Environmental Studies in a 3D geometry and 2D simulation results of Xie et al. [24]. Building arrays were configured in a two-dimensional environment. Free streamwise velocity in the computational domain of the CFD model was considered to be higher than wind tunnel experimental model so that it enters from the height of the roof $(\Delta \mathrm{u} / \mathrm{U} \sim 0.25)$. Fig. 2 shows the validation results of the normal vertical profiles for temperature and horizontal flow rate of the centerline of the urban street canyon. As can be seen, the accuracy of the CFD model is confirmed using experimental data and simulation results. The findings revealed an average error percentage of $10.83 \%$ between the measured (simulation data in this

\footnotetext{
${ }^{3} P M V=\left(0.303 e^{-0.036 M}+0.028\right) L$, where $\mathrm{L}=$ Thermal load: defined as the difference between the internal heat production and the heat loss to the actual environment for a person at comfort skin temperature and evaporative heat loss by sweating at the actual activity level.

${ }^{4} \mathrm{PPD}=100-95 . \exp \left(-0.03353 . P M V^{4}-0.2179 . P M V^{4}\right)$

${ }^{5} \mathrm{M}$ : Metabolic Rate- the rate at which metabolism occurs in a living organism.

${ }^{6}$ Clothing; put clothes on (oneself or someone); dress.
} 
study) and CFD predicted values (experimental data) for air velocities. In overall, the current model velocity and temperature results showed good agreement with previous works, in particular with the numerical model of Xie et al. [24]. Although a slight difference was observed between the numerical and experimental data, a similar trend was still observed between both methods. Due to the larger free-stream wind velocity, the change in the stream-wise velocity calculated by the present CFD model is slightly higher than the wind tunnel measurements.

\section{Results and discussion:}

\subsection{The patterns of air flow and pollution transport in isothermal roof conditions:}

Different aerodynamic parameters of urban canyons in isothermal condition have been widely studied in different physical layouts [16,20,21,24,41]. Here, different roof surfaces in isothermal condition are evaluated in terms of aerodynamic parameters and pollutants dispersion. Then, the results are compared to those predicted by a non-isothermal condition.

Fig. 3 ( $a, b$ and c) shows the air flow pattern and vectors, turbulent kinetic energy and distribution of the pollutants in the street canyons with an aspect ratio of $\mathrm{H} / \mathrm{W}=0.5$ for gabled roof with rise/run ratio zero, 12 and domed roof in an isothermal condition. Also, the distribution of air flow, TKE, and pollutants in the street canyons with aspect ratios of $\mathrm{H} / \mathrm{W}=1.0$ and 2.0 and with different roof shapes are shown in Figs. 4 and 5 ( $a, b$ and c). Notice that for sake of brevity, the CFD results for gabled roof with the rise/run ratios of 3,6 , and 9 have not been reported here.

The present CFD results in Fig. 3(a) indicate that in isothermal conditions in an urban canyon with a ratio of $\mathrm{H} / \mathrm{W}=0.5$, where vortex flow is a WIF (wake interference flow), a large clockwise rotating primary vortex is formed in the center of the canyon and a small counter-clockwise-rotating secondary vortex is formed in the leeward side near the ground in the case of flat roof (Fig. 3(a-1)). In this case, the concentration of pollutants accumulated in the leeward space is greater (Fig. 3(c-1)). The intensity of turbulence kinetic energy (TKE) near roof surfaces, windward, and the central areas is higher than the leeward area (Fig. 3(b-1)). The results of other studies showed a relation between the various factors such as patterns of airflow and pollutant concentrations in isothermal conditions [24] that confirmed the accuracy of the present CFD results at the same conditions.

It is found that by increasing the rise/run ratio, the area of primary vortex becomes greater and spreads to the roof peak; leeward secondary vortex also becomes smaller and a windward tertiary vortex is formed. Distribution of TKE and pollutants for different roof shapes in the street canyon with $\mathrm{H} / \mathrm{W}=0.5$ is shown in Figs. 3(b) and 3(c). It can be observed that an increase in the rise/run ratio, increases the magnitude of primary and tertiary vortices (Fig. 3(b-2)) and also transfers pollutants to higher heights leeward areas (Fig. 3(c-2)). In addition, an increase in the slope of the roof also increases the turbulent kinetic energy of the canyon to the extent that it also covers the leeward area. In the domed roof model (Fig. 3(a-3)), a clockwise-rotating central vortex in the canyon increases the leeward pollutant concentration and also intensifies the turbulent kinetic energy in the canyon and the leeward area (Fig. 3(b-3, c-3)).

As shown in Fig. 4(a), in regular urban canyons with a ratio of $\mathrm{H} / \mathrm{W}=1$, airflow regime is $\mathrm{SF}$ (skimming flow) and when the airstream over the canyon is from left to right, a large clockwise-rotating vortex is formed in the center of the canyon. There are also two very small vortices in the corners of the leeward and windward regions in the case of flat roof (Fig. 4(a-1)). In regular canyons with flat roof, the intensity of turbulent energy near roofs and the windward region is greater than the centerline and leeward region; therefore, leeward pollutant concentration is greater (Fig. 4(b-1, c-1)). It is found that by increasing the rise/run ratio of roofs from zero to 6 , the magnitude of the primary central vortex becomes greater and spreads toward the roof level (For example see Fig. 4(a-1)); but in the ratio of 9 and 12 (For instance, see Fig. 4(a-2) that has been depicted for the case of rise/run ratio 12), central vortex goes upward (close to 
roof level) and a counter-clockwise-rotating secondary vortex is formed in the center of the canyon [20,24]. According to Fig. 4(a), which shows the air flow pattern in different models, by increasing the rise/run ratio, the high-altitude vortex near the roof surfaces becomes larger. Meanwhile, dome-shaped roofs in configuring regular canyons form a clockwise-rotating large vortex inside the canyon (Fig. 4(a3)).

Fig. 4(b) and 4(c) show the distribution of turbulent kinetic energy and pollutants in the regular street canyons $(\mathrm{H} / \mathrm{W}=1)$ in an isothermal condition. As can be found by increasing the rise/run ratio to 9 and 12 , Fig. 4(b-2) refers to the case with rise/run ratio 12, the intensity of turbulent kinetic energy is dropped in the lower areas of the canyon and is increased in higher areas of the canyon, especially near the roof. The result is the transfer of pollutants and increase of its concentration in the windward region and near roof surfaces (Fig. 4(c-2)). The main reason for the accumulation of contaminants in the windward area is the direction of rotation of the vortex inside the canyon, which is counter-clockwise (Fig. 4(a-2)). The results show that dome-shaped roofs, compared with slanted roofs, increase the intensity of turbulent energy inside the canyon for the lower areas (Fig. 4(b-3)). The highest concentration of pollutants in the domeshaped canyons is in the leeward area (Fig. 4(c-3)). It should also be noted that differences between the measured parameters namely, patterns of airflow, turbulent kinetic energy and pollutant concentrations, with run/rise ratios of zero and 3 in three large (0.5), regular (1) and deep (2) urban canyons are minimal.

Wind flow in deep canyons with $\mathrm{H} / \mathrm{W}$ ratio of 2 forms SF regimes. As Fig. 5 (a and c) and data resulting from the study of Xie et al. [24] shows, the difference of the airflow pattern in H/W ratios of 1 and 2 is in vortices created in urban canyons. In isothermal conditions, two counter-clockwise-rotating vertical vortices are created in a deep canyon in the middle of the urban road. The smaller vortex is in the bottom of the canyon (lower half) and rotates counter-clockwise for the street canyon with flat configuration (Fig. 5(a-1)). The vortex causes the concentration of pollutants in the lower heights to be more in the windward region, as compared to the leeward region (Fig. 5(c-1)). In deep canyons with domed roof layouts (Fig. $5(a-3))$, three vortices of the same size are formed at different heights and the distribution of pollutants is observed to be similar to sloping roofs with a rise/run ratio of 6.

According to Fig. 5(b-1); the intensity of turbulence energy near the roof in deep canyons $(\mathrm{H} / \mathrm{W}=2)$ is greater than the other ratios $(\mathrm{H} / \mathrm{W}=0.5$ and $\mathrm{H} / \mathrm{W}=1)$, which is due to increased roughness ${ }^{7}$ [55], as the turbulence energy near the roof of the building is more in the windward area. In deep canyons with domeshaped and slanted roofs in rise/run ratio 6,9 and 12, the primary vortex moves toward higher altitudes by increasing heights and smaller vortex at the middle of the canyon finds higher levels of development as at the end of the canyon, i.e. the canyon floor, a third clockwise-rotating vortex is formed. Fig. 5(a-2 and a3 ) clearly shows the third clockwise-rotating vortex for slanted roof in rise/run ratio 12 and dome-shaped. Formation of the third vortex increases the concentration of pollutants in the leeward area (Fig. 5(c-2 and $\mathrm{c}-3)$ ), and also increase in the slope of the roof is associated with a reduction of the intensity of turbulent kinetic energy within urban canyons (Fig. 5(b-2 and b-3)).

Fig. 6(a) shows airflow velocity in the center line of the canyon for 6 different models of canyons with ratios of $\mathrm{H} / \mathrm{W}=0.5$.

In the lower levels of the canyon $(\mathrm{H}=0.1)$, the highest airflow velocity is for streets with domed roof configuration. In the middle levels of the canyon $(\mathrm{H}=0.55)$, with an increase in roof slope, the airflow

\footnotetext{
${ }^{7}$ The upstream and downstream region of the computational domain in which the actual obstacles are modeled implicitly, i.e., their geometry is not included in the domain but their effect on the flow can be accounted for in terms of roughness. According to Blocken et al. [55], considering roughness of the roofs leads to improving the aerodynamic, turbulent kinetic energy and also thermal behavior at the outdoor. Existing rough surfaces of buildings and streets in urban canyons cause considering roughness in the model.
} 
velocity in that region increases, and when we get to the higher elevations near the surface of the roof $(\mathrm{H}$ $=1$ ), an increase in slope decreases the air flow velocity.

Airflow velocity in canyons with H/W ratio of 1 in Fig. 6(b) shows that by increasing the slope of the roof, the circulation and natural ventilation flows were the lowest at the bottom of the canyon, while dome-shaped canyons formed the highest airflow velocity in lower and middle elevations. In upper elevations of regular urban canyons, ratios of zero, 3, 12, 9 and 6 have the highest airflow velocity, respectively.

By increasing $\mathrm{H} / \mathrm{W}$ ' ratio and creating deep urban canyons, airflow velocity within the canyon decreases dramatically, so airflow speed in the bottom of the canyon in all models is very low and near zero. By increasing roof surface, the airflow velocity in middle levels decreases and higher levels of canyons with flat and slanted roofs have the highest airflow velocity. It should also be noted that by increasing the H/W ratio, the airflow velocity in the vicinity of the roof is less than other ratios $(\mathrm{H} / \mathrm{W}=0.5,1)$. The main cause of reduction of wind flow velocity is the formation of turbulence caused by roughness created near the upper levels (Fig. 6(c)).

\subsection{The patterns of air flow and pollution transport in non-isothermal conditions:}

Several studies showed that in addition to the geometrical parameters, heating effects and the temperature difference can produce thermal turbulence and change mechanical circulation within the canyons [8]. The geometry of urban canyon and its aspects' ratios are important factors in the emergence of flotation parameters [56]. In this study and in the next section, the effect of both thermal buoyancy (by comparing with flow distribution of isothermal and non-isothermal) and aerodynamic forces (by comparing models with different physical layout) on the pattern of air flow and distribution of pollutants in urban canyons is investigated.

In this section, the distribution of the air flow pattern, TKE, and concentration of pollutants in the street canyons for different roof shapes in non-isothermal condition are shown in Figs. 8, 10 and 12. Also Figs. 7, 9 and 11 show the airflow velocity in center areas for different roof shapes in non-isothermal condition. According to Fig. 7, in non-isothermal conditions, airflow velocity in central regions is higher than isothermal conditions for all models in street canyons with aspect ratio 0.5 , except the model with rise/run 12.

According to Fig. 8(a-1), in street canyons with flat configuration and $\mathrm{H} / \mathrm{W}$ ratio of 0.5 , the thermal effect of the roof and subsequently the buoyancy force inside the canyon causes the formation of a large clockwise-rotating vortex in the center of the canyon. As shown in Figs. 3(b-1) and 8(b-1), the temperature difference between the air and the roof, along with the production of thermal buoyancy and turbulence, increases turbulence kinetic energy around the roof.

Formation of a huge vortex inside the canyon leads to higher concentration of pollutants in the leeward region; as can be seen in Fig. 8(c-1), the concentration of $\mathrm{CO}$ in this case is very low in the central and windward regions. It is found that by increasing the slope of the roof, the secondary counter-clockwiserotating vortex is formed in the leeward region and the magnitude of this vortex increases, especially, in the rise/run ratio 12. In addition, the third counter-clockwise-rotating vortex is seen in the windward region (see Fig. 8(a-2)). In dome-shaped roofs, the magnitude of the secondary vortex is decreased and the primary central vortex encompasses all levels of the canyon (Fig. 8(a-3)). Dome-shaped roofs, compared with sloping roofs, increase turbulence intensity in the canyon, only in the windward area (Fig. 8(b-3)).

By increasing the height and slope of the roof, primary vortex expands to higher levels. The result of increasing the temperature and slope of the roof is an increase in the turbulent kinetic energy near the 
roofs surface and windward high-altitude regions (Fig. 8(b-1, b-2)). Increasing turbulent energy intensity in the mentioned areas is associated with a reduced concentration of pollution in these areas (Fig. 8(c-2)).

According to the contours in Fig. 8 (b, c), increased the height of the roof is followed by the highest concentration of pollution in the central area of the bottom of the canyon and the surrounding area of the leeward roof surface. Moreover, for various rise/run ratios and also domed roofs, it can be noted that the main reason is a reduction of turbulence (turbulent kinetic energy) and natural ventilation in these areas that reduces the transfer of pollution from the emission source (see Fig. 8(c-2 and c-3)). In general, it can be concluded that by increasing temperature of urban areas and forming buoyancy, thermal turbulence increases.

Comparison of airflow velocity for regular canyons at isothermal and non-isothermal conditions in Fig. 9 shows that in passages with an $\mathrm{H} / \mathrm{W}$ ratio of 1 , the airflow velocity inside the canyon increases in central regions by increasing the temperature in low-slope roofs (zero, 3 and 6). But in steep roofs (9, 12, etc.), increasing roof surface temperature will not have much impact on the wind flow velocity in urban canyons. The wind flow speed is a bit more than isothermal conditions just in high altitudes $(H=1)$, which is due to increased turbulence in these areas. Also in regular canyons with dome-shaped roofs, increase in roof surface temperature decreases airflow velocity in windward and leeward areas, as compared to isothermal conditions.

In addition to increasing turbulent kinetic energy in regions near the roof and windward areas, the effect of thermal buoyancy force around the roof in canyons with $\mathrm{H} / \mathrm{W}$ ratio of 1 leads to the formation of a single clockwise-rotation vortex in urban canyons (Fig. 10(a-1)). It is found that in rise/run ratios zero in Fig. 10(c-1), 3 and 6, the concentration of pollutants in the leeward region is more than other areas; i.e. central and windward regions. By increasing the height of the roof (models rise/run $=3$ and rise/run $=6$ ), the central vortex spreads to higher altitudes, and by increasing turbulence, pollutant concentrations decreases in the central and windward regions and the highest concentration of pollution is in the leeward region; the ratio of rise/run $=6$ ).

By increasing height of dome-shaped and steep roofs, the primary vortex is transferred to higher areas of the canyon. Therefore, two vortices, one in the windward (clockwise-rotating) and the other in the leeward (counter-clockwise-rotation) region, are formed in the lower areas of the canyon. The overlap of two vortices at the bottom of the canyon with the $\mathrm{CO}$ emission source leads to the distribution of pollution in all areas of the canyon, especially in the center, so that it covers altitudes near the roof (see Fig. 10(a-2 and a-3)).

In the contours of turbulent kinetic energy (TKE) in Fig 10(b-2 and b-3), it can be seen that reducing the street width and the roof height significantly decreases turbulence intensity in the lower areas of the canyon and the highest intensity is in the upper areas of the canyon (between the roofs).

The simulation results of this study, as observed in Fig. 11, show that the difference in airflow velocity in deep canyons with $\mathrm{H} / \mathrm{W}$ ratio of 2 is less than other ratios $(\mathrm{H} / \mathrm{W}=0.5$ and $\mathrm{H} / \mathrm{W}=1)$ under isothermal and non-isothermal conditions. The existence of short roofs (rise/run $=0$ and rise/run $=3$ ) in deep canyons increases the airflow velocity in the central regions of the canyon, as compared to isothermal conditions.

Fig. 12 (a,b and c) shows the air flow structure and distribution of turbulent kinetic energy and pollutants in the deep street canyons $(\mathrm{H} / \mathrm{W}=2)$ in non-isothermal condition. Similar to Figs. 3, 4, 5, 8 and 10, for sake of brevity and clarity, the CFD results for gabled roof with the rise/run ratios of 3, 6, and 9 have not been shown in Fig. 12.

In Fig. 12(a-1), by increasing $\mathrm{H} / \mathrm{W}$ ratio in deep urban canyons $(\mathrm{H} / \mathrm{W}=2)$, a primary clockwise-rotating vortex is formed. Also, highest pollution concentration is in the leeward area, which is also transferred to 
surfaces near the roof by increasing the slope of the roof in rise/run ratios 12 and domed roofs (Fig. 12(c2 and c-3)). It is found that, in canyons with a rise/run ratio of 6, a secondary vortex is formed in lower levels that increases the concentration of pollution in leeward, central, and windward regions of the canyon. Also, the magnitude of the secondary vortex increases with increase in rise-run ratio (rise/run = 9) and pollutants accumulate in the windward area.

Furthermore, by increasing the height of the roof, distribution of pollution in different areas of canyon forms various patterns. In dome-shaped and slanted roofs (rise/run $=12$ ), multiple vortices are created in the lower levels of the canyon, which increase the CO concentration in the leeward (low levels), windward and central (top level) regions (Fig. 12(c-2, c-3)).

Increase in the roof surface temperature and $\mathrm{H} / \mathrm{W}$ and rise/run ratios increase turbulent kinetic energy and pollution concentration in high altitudes of the canyon and develop over the interface between the roofs, which is often the case for dome-shaped roofs. Refer to Fig. 12(b, c).

The increase of flat and low-slope roof surface temperature $(0 \leq$ rise / run $\leq 3)$ in a variety of urban canyons with $\mathrm{H} / \mathrm{W}$ ratios of $0.5,1$, and 2 creates a single central clockwise-rotating vortex within the canyon that transfers pollutants to the leeward region. By increasing the height of the roof at regular canyons, pollution transfer is changed and distributed at all levels of the canyon.

\subsection{Structure of thermal patterns in non-isothermal conditions:}

Distribution of temperature in the street canyon for different roof shapes with three aspect ratios is shown in Fig. 13. Also Fig. 14 show the static temperature in leeward (a), central (b) and windward (c) areas for street canyons with an $\mathrm{H} / \mathrm{W}$ ratio of 1 .

Temperature isotherms space for $\mathrm{H} / \mathrm{W}$ ratio of 0.5 that is shown reveals that the central vortex, with its extensive coverage, is able to draw the least warm air of the roof surface into the canyon. While increasing the slope of the roof increases the amount of heat mass trapped by the vortices at the bottom of the canyon that are observed in windward and leeward areas and near the ground. With the increase in roof height, temperature density near the leeward roof surface is maximum and is passed to central areas by airflow. It was found that by increasing height and slope of roofs in these canyons, the airflow velocity and turbulence in the leeward area is increased and transfer of pollution in this area is accelerated.

According to Fig. 13, in urban passages with an H/W ratio of 1, existence of low- and medium-slope roofs (rise / run $=0,3,6$ ) transfers their heat to vicinity of internal surfaces (windward surface, leeward surface and ground) because of the formation of a single central vortex, but by increasing the slope of the roof (domed roof and the rise / run =9, 12), shown in Fig. 13(d,e,f), and the formation of two vortices at the bottom of the canyon and a single vortex above the canyon, heat is distributed in all parts of the canyon. It can be observed that the temperature is very high at high altitudes of the canyon and the interface between roofs, which is the main cause of the increase in turbulent intensity and heat transfer in this area.

As can be seen; roof surface heat is easily trapped in the canyon, which further increases the temperature in canyons with $\mathrm{H} / \mathrm{W}$ ratio of 2 because of narrow passages and reduction of the flow of air in this area. With the increase of height and slope of the roof with rise/run ratios of 6 and 9, wind flow passing through the roof surface quickly enters the canyon and increases the temperature of surfaces and areas within the canyon. According to the results of this study, in canyons with dome-shaped and slanted roofs (rise/run $=12$, etc.), heat trapped in the upper levels of the canyon is more and less heat will reach to lower levels of the canyon.

It was found in $\mathrm{H} / \mathrm{W}$ ratio of 0.5 , an increase in roof slope and application of the roof surface and fluid temperature difference increases the temperature at different areas of the canyon. According to Fig. 14 for 
$\mathrm{H} / \mathrm{W}$ ratio 1 in different areas; leeward, center and windward, increasing the slope and height of the roof in the leeward area increases the air temperature in the canyon (Fig. 14(a)). The temperature of the canyon in higher central locations also increases by increasing the slope of the roof. Rise/run ratios of 6 and 9 have the greatest temperature at lower levels of the central area of the canyon (Fig. 14(b)). In windward highlands, dome-shaped and slanted roofs have a high temperature, and the temperature conditions of the central and windward regions with an H/W ratio of 1 are approximately similar (Fig. 14(c)).

Temperature charts with an H/W ratio of 2 show that in the lower and middle levels of the canyon, the dome-shaped roof has the lowest trapped heat in the three areas. But in the upper parts of the canyon, masses trapped in these areas increase with the increase of height of the roof. However, the rise/run $=6$ model in the central and windward regions and the rise/run $=9$ model in the leeward region experiences high temperature at different levels.

Moreover, the influence of temperature difference between the roof and air flow $(\Delta T)$ on the aerodynamic and thermal parameters in street canyons with an aspect ratio of $\mathrm{H} / \mathrm{W}=0.5,1$ and 2 was studied for the dome roof and the results are not detailed in the article. The cause of selection of dome roof refers to the considerable thermal effects of this roof at isothermal and non-isothermal conditions as shown in the prior results. The results show that for the broad canyons, $\mathrm{H} / \mathrm{W}=0.5$, by an increase in $\Delta \mathrm{T}$ the turbulence caused by thermal buoyancy force also increases, resulting in an increase of airflow and leading to a reduction in pollutant concentration. For regular and deep canyons $(\mathrm{H} / \mathrm{W}=1$ and 2$)$ it is seen that with increasing $\Delta \mathrm{T}$, pollutant concentration increases because of heat trapping, reduced street width, and reduction in the turbulence intensity of heat and flow rate within the urban canyons.

\subsection{Investigating thermal comfort in non-isothermal conditions:}

Heterogeneous heat distribution in urban passages that is caused by various physical and climatic factors is the most common problem of pedestrians during the day. Solar thermal instability and formation of unstable conditions in the urban boundary layer affect thermal comfort in these spaces more than other factors, which require further investigation [57]. Enhancing the quality of urban open spaces and improving citizens' comfort in these areas is essential; and it is one of the most important goals of engineers, planners, and urban designers. Thus, climatic parameters [9], physical parameters [27] such as morphology and geometry of urban passages (the ratio of H/W, SVF factor, the roof shape, etc.) and physiological and psychological parameters [104] will be important in improving thermal comfort.

The use of bio meteorological indicators and steady-state models is very useful in investigating climatic impacts on thermal comfort of open spaces and local micro-climates. PMV-Fanger (1982) model is one of the important indicators that are widely used to predict the thermal response of mean vote (PMV) and the percentage of dissatisfaction with the thermal environment (PPD) of the space. The scale of this index can be measured on 7 points [58].

In isothermal conditions, all research models are at the thermal comfort range of $0.04 \leq \mathrm{PMV} \leq 0.39$ because of constant temperature $\left(25^{\circ} \mathrm{C}\right)$, but as the roof surface temperature increases $\left(35^{\circ} \mathrm{C}\right)$, some models move out of this range.

Fig. 15 shows the predicted mean vote (PMV index) in street canyons with aspect ratios of $\mathrm{H} / \mathrm{W}=1$ (a) and predicted percentage dissatisfied (PPD index) in central regions with aspect ratios of $\mathrm{H} / \mathrm{W}=0.5,1,2$ (b) for non-isothermal condition in leeward, central and windward areas.

The results of investigating thermal comfort in this study show that in canyons with $\mathrm{H} / \mathrm{W}$ ratio of 0.5 , increase in height and slope of roof in slanted roofs with rise/run=12 and dome-shaped roofs causes the thermal comfort in different areas (leeward, windward, and central regions) move away from the normal 
condition $^{8}$ (out of neutral condition; $\left.(-0.5)-(+0.5)\right)$ [25]. In slanted roofs with a ratio of rise/run $=12$, all three windward, leeward, and central regions showed lower levels of thermal comfort. While in urban canyons with dome-shaped roofs, the leeward region at middle levels, the central area of upper levels and the windward region at lower levels lack thermal comfort. As was seen in the temperature charts, the temperature inside the canyon in these models is in a high range as compared to other models. Other models are at the thermal comfort range at all surfaces and levels. According to the figures presented in Fig. 15(a), in urban canyons with $\mathrm{H} / \mathrm{W}$ ratio of 1, models with low-slope and flat roofs are in the thermal comfort range in ratios of rise/run $=0$ and 3.

1. Models with rise/run ratios of 9 and 12 are out of the thermal comfort range in all levels $(H=0-1)$ in the leeward region.

2. The model with rise/run ratio of 6 is out of thermal comfort range in all heights $(\mathrm{H}=0-1)$ and models with rise/run ratios of 9 and 12 are out of this range at higher levels of the canyon $(\mathrm{H} \geq 0.7)$.

3. The model with rise/run ratio of 6 is in a little hot range in the lower levels of the canyon $(\mathrm{H} \leq 0.5)$ and models with rise/run ratios of 9 and 12 are the same at higher levels $(\mathrm{H} \geq 0.7)$.

4. It was also observed that urban canyons with a dome-shaped roof configuration are associated with lack of thermal comfort in the upper levels of passages $(\mathrm{H} \geq 0.5)$ in three leeward, windward, and central regions.

The results of this study shows that in deep canyons with $\mathrm{H} / \mathrm{W}$ ratio of 2 , flat roofs with a rise/run ratio of 0 have thermal comfort at different levels, which is similar to regular canyon models.

1. Models with rise/run ratios of 6 and 9 are at a little in the hot range in the leeward region at all levels $(\mathrm{H}=0-1)$ and the model with a rise/run ratio of 12 is in this range at high altitudes $(\mathrm{H} \geq 0.7)$.

2. Models with rise/run ratios of 6 and 9 are not in the thermal comfort range in the central region at all levels $(\mathrm{H}=0-1)$ and the model with a rise/run ratio of 12 is not in this range at high altitudes $(\mathrm{H} \geq 0.8)$.

3. Models with rise/run ratios of 6 and 9 are not in the thermal comfort range in the windward region at all levels $(\mathrm{H}=0-1)$ and models with rise/run ratios of 3 and 12 are not in this range at high altitudes $(\mathrm{H} \geq 0.8)$.

4. Deep urban canyons with a dome-shaped roof configuration are associated with lack of thermal comfort in the upper levels $(\mathrm{H} \geq 0.8)$ in three leeward, windward, and central regions.

The results of dissatisfaction with the thermal environment (PPD index) in this study and the charts of Fig. 15(b) show that in broad canyons with an H/W ratio of 0.5 (Fig. 15(b-1)) when the height of the roof is increased, dome-shaped roofs and highly slanted roofs are not in the range of users' satisfaction with the thermal environment. In urban canyons with an H/W ratio of 1 (Fig. 15(b-2)) and 2 (Fig. 15(b-3)), dome-shaped and slanted models with rise/run ratios of 6,9 , and 12 have the highest percentage of dissatisfaction with the thermal environment. Fig. 15(b) shows the percentage of dissatisfaction with the thermal environment for the central line of different models.

\section{Conclusion}

In the present study, the effect of roof surface heating and pathway configuration was studied for 18 configurations by CFD model within a two-dimensional framework. The results showed that warming of the roof surfaces leads to the formation of thermal buoyancy force in the upper areas of the urban canyon. Buoyancy force along with the production of thermal turbulence at different levels of the canyon led to significant changes in the structure of the airflow pattern and transport of pollutants. In isothermal

\footnotetext{
${ }^{8}$ normal condition $=$ acceptable condition $=$ neutral condition
} 
conditions, the important factor in the pattern of the airflow current in the urban canyon was its geometry and configuration, i.e. parameters such as the H/W ratio of the canyon and rise/run ratio of the roof that were examined in this study.

For isothermal conditions, broad canyons $(\mathrm{H} / \mathrm{W}=.5)$ made the wake interference flow pattern by forming two large (primary) and small (secondary) vortices.

It was found that by increasing height and slope of roofs in these canyons, the airflow velocity and turbulence in the leeward area is increased and transfer of pollution in this area is accelerated.

It was shown that by increasing the height of the roof and rise/run ratio and minimizing the leeward region vortex, $\mathrm{CO}$ concentration decreases in this area. In addition, the temperature in the vicinity of internal surfaces of canyon increases when the roof surface temperature increases and also pollution concentration near the ground and leeward areas increases due to the formation of a large vortex.

The buoyancy force in non-isothermal conditions led to an increase in airflow velocity inside the canyon, as compared to the isothermal model. In non-isothermal conditions, increasing the height and slope of the roof also increased the temperature in the urban canyon and formation of a small vortex in the leeward region was observed, which reduced $\mathrm{CO}$ transfer and concentration in this area, as compared to lowslanted roofs.

In regular urban canyons with an $\mathrm{H} / \mathrm{W}$ ratio of 1 , producing a central vortex leads to the formation of $\mathrm{SF}$ (skimming flow) airflow regime. In this case, the highest concentration of pollution is in the leeward area. Increasing the roof slope resulted in the development of vortex in the higher locations and the $\mathrm{CO}$ concentration also increased along the surface of the roof.

In regular canyons with dome-shaped or slanted roofs, a secondary vortex was formed at the bottom of the canyon that increased the concentration of pollution in the windward area. It was observed that by increasing the height of the roof, the lowest circulation and ventilation flows at the bottom of the canyon occurs.

It was found that increasing the roof surface temperature of low-slanted roofs with rise/run ratios of 0,3 , and 6 increases airflow velocity inside the canyon. While for the highly-slanted roofs $(9,12$, etc.), roof surface temperature rise had an insignificant impact on the airflow velocity of the urban canyon.

Increasing the roof surface temperature in regular canyons with dome-shaped roofs reduced the airflow velocity of windward and leeward regions. The thermal effect of roofing causes the pollutant transfer to the leeward area using a primary vortex inside the canyon. The main reason of pollutant accumulation in the leeward area is the direction of vortices' rotation and low value of air velocity in that region. Increasing the height and slope of the roof also increased the pollutant concentration in the canyon, particularly in the central region, due to the formation of two other vortices in the lower levels of the canyon.

Wind flow in deep canyons with an H/W ratio of 2 formed the skimming flow regimes. In these passages, two counter-clockwise-rotating vortices were formed vertically in the middle of a passage, resulting in higher pollutant concentration in lower levels of the windward area of the canyon.

The increase in roof height also created a tertiary vortex and transferred pollutants toward the leeward area and increased $\mathrm{CO}$ trap in the canyon. In addition, the airflow velocity difference in deep canyons $(\mathrm{H} / \mathrm{W}=2)$ was insignificant compared to wide passages $(\mathrm{H} / \mathrm{W}=0.5$ and 1$)$ for isothermal and nonisothermal conditions. Short roofs (rise/run $=0$ and rise/run $=3$ ) in deep canyons increased the airflow velocity inside the canyon in three leeward, windward, and central areas in non-isothermal condition, as compared to isothermal one. Moreover, by increasing the height and roof surface temperature, turbulent 
kinetic energy and the concentration of pollution in the upper levels of the canyon is increased and developed to the space between the sloped-shape roofs.

An increase in height and slope of the roof in broad canyons caused the thermal comfort of leeward, windward, and central regions move away from the neutral conditions. In regular canyons and the height of the roof in highly slanted models (rise/run $\geq 6$ ) reduces the thermal comfort. On the other hand, canyons with a dome-shaped roof configuration are associated with lack of thermal comfort in the upper levels of passages $(\mathrm{H} \geq 0.5)$ in three leeward, windward, and central regions. In deep canyons with an $\mathrm{H} / \mathrm{W}$ ratio of 2 , high levels of thermal comfort exist only in structures with flat roofs. By increasing roof height, the PMV index leaves the comfort range and moves toward the hot range. The results showed that the formation of thermal buoyancy force in the urban canyons is effective in improving human thermal comfort in urban areas. In general, roof surface and fluid temperature difference increased airflow velocity and pollutant transfer in urban canyons. But increasing the height and slope of structures around urban areas reduced the effect of buoyancy force on improving thermal comfort and quality of air inside the canyon. Finally, the thermal buoyancy force led to the reduction of thermal comfort simultaneously with the increasing the ratio of $\mathrm{H} / \mathrm{W}$ of passages and roof height, wind comfort, and air quality inside regular and deep urban canyons.

There are many factors that affect the airflow and thermal distribution in real urban environments but in a controlled case such as in this simulation, it shows that the roof shape and heating have an effect on the urban conditions.

\section{Nomenclature}

$\mathrm{C}$

pollutant concentration $\left(\mathrm{kmol} / \mathrm{m}^{3}\right)$

G acceleration due to gravity $\left(\mathrm{m} . \mathrm{s}^{-2}\right)$

$\mathrm{D}_{\mathrm{H}} \quad$ hydraulic diameter

A Area section of the duct or pipe $\left(\mathrm{m}^{2}, \mathrm{ft}^{2}\right)$

$\mathrm{P} \quad$ Perimeter of the duct or pipe $(\mathrm{m}, \mathrm{ft})$

a

Length of rectangular duct (m)

b

Width of rectangular duct (m)

Gr Grashof number $\mathrm{Gr}=$ ??g $\Delta \Theta \mathrm{H}^{3} /$ ?? ${ }^{2}$

$\mathrm{H} \quad$ height of the buildings (m)

$\mathrm{H}_{1} \quad$ height of the leeward building (m)

$\mathrm{H}_{\mathrm{w}} \quad$ height of the windward building (m)

$\operatorname{Re} \quad$ Reynolds number $\mathrm{Re}=\mathrm{UH}_{1} /$ ?

S pollutant source strength

$\mathrm{U} \quad$ ambient wind speed $\left(\mathrm{m} . \mathrm{s}^{-1}\right)$

W width of the street $(\mathrm{m})$ 


$\begin{array}{ll}\Delta \Theta & \text { temperature difference } \Delta \Theta=\Theta_{\mathrm{f}}-\Theta_{\mathrm{n}} \\ \kappa & \text { molecular diffusivity } \\ v & \text { molecular kinematic viscosity } \\ \mu & \text { dynamic viscosity }(\mathrm{kg} / \mathrm{m}-\mathrm{s}) \\ \rho & \text { density }\left(\mathrm{kg} \cdot \mathrm{m}^{-3}\right) \\ \beta & \text { thermal expansion coefficient } \\ \Theta & \text { air temperature }\left({ }^{\circ} \mathrm{C}\right) \\ \Theta_{\mathrm{n}} & \text { ambient air temperature }\left({ }^{\circ} \mathrm{C}\right) \\ \Theta_{\mathrm{f}} & \text { surface temperature }\left({ }^{\circ} \mathrm{C}\right)\end{array}$

\section{References}

[1] A.H. Rosenfeld, H. Akbari, S. Bretz, B.L. Fishman, D.M. Kurn, D. Sailor, H. Taha, Mitigation of urban heat islands: materials, utility programs, updates, Energy and Buildings 22 (3) (1995) 255-265.

[2] M.A. Palmer, D.P. Lettenmaier, N.L. Poff, S.L. Postel, B. Richter, R. Warner, Climate change and river ecosystems: protection and adaptation options, Environmental Management 44 (6) (2009), 10531068.

[3] M. Santamouris (Editor), Energy and Climate in the Urban Built Environment. James and James Science Publishers, London, 410p. Santamouris, M., 2006. Environmental Design of Urban Buildings: An Integrated Approach. Routledge Publisher, (2001) 348p.

[4] J.M. Wallace, P.V. Hobbs, Atmospheric Science: An Introductory Survey, Academic Press, Oxford, (2006) 411p.

[5] US Environmental Protection Agency (EPA), Reducing Urban Heat Islands: Compendium of Strategies, Urban Heat Island Basics, (2008) 22p.

[6] J. Chen, H. Wang, H. Zhu, Analytical Approach for Evaluating Temperature Field of Thermal Modified Asphalt Pavement and Urban Heat Island Effect, Applied Thermal Engineering 113 (2017) 739748.

[7] T. Stathopoulos, H. Wu, J. Zacharias, Outdoor human comfort in an urban climate, Building and Environment 39 (3) (2004) 297-305.

[8] J.J. Kim, J.J. Baik, Effects of street-bottom and building-roof heating on flow in three-dimensional street canyons, Advances in Atmospheric Sciences 27 (3) (2010) 513-527.

[9] C. António, J. B. Monteiro, C. F. Afonso, Optimal topology of urban buildings for maximization of annual solar irradiation availability using a genetic algorithm, Applied Thermal Engineering 73 (1) (2014) 424-437.

[10] S. Houda, N. Zemmouri, R. Athmani, R. Belarbi, Effect of urban morphology on wind flow distribution in dense urban areas, Revue des Energies Renouvelables 14 (1) (2011) 85 - 94.

[11] I. Eliasson, B. Offerle, Wind fields and turbulence statistics in an urban street canyon, Atmospheric Environment 40 (1) (2006) 1-16. 
[12] T. Ayata, Investigation of building height and roof effect on the air velocity and pressure distribution around the detached houses in Turkey, Applied Thermal Engineering 29 (8-9) (2009) 1752-1758.

[13] E. Jamei, P. Rajagopalan, M. Seyedmahmoudian, Y. Jamei, Review on the impact of urban geometry and pedestrian level greening on outdoor thermal comfort, Renewable and Sustainable Energy Reviews 54 (1) (2016) 1002-1017.

[14] J.J. Baik, J.J. Kim, A numerical study of the effects of ambient wind direction on flow and dispersion in urban street canyons using the RNG k- $\varepsilon$ turbulence model, Atmospheric Environment 38 (2004) 30393048.

[15] S. Vardoulakis, B.E.A Fisher, K. Pericleous, N. Gonzalez-Flesca, Modelling air quality in street canyons: a review, Atmospheric Environment 37 (2) (2003) 155-182.

[16] X.M. Xie, Z. Huang, J.S. Wang, Impact of building configuration on air quality in street canyon, Atmospheric Environment 39 (25) (2005) 4519-4530.

[17] I. Abohela, N. Hamza, S. Dudek, Effect of roof shape, wind direction, building height and urban configuration on the energy yield and positioning of roof mounted wind turbines, Renewable Energy 50 (1) (2013) 1106-1118.

[18] Y. Huang, M. Jin, Y. Sun, Numerical studies on airflow and pollutant dispersion in urban street canyons formed by slanted roof buildings, Journal of Hydrodynamics 19 (1) (2007)100-106.

[19] M.F. Yassin, K. Radka, Z. Janour, Impact of street intersections on air quality in an urban environment, Atmospheric Environment 42 (20) (2008) 4948-4963.

[20] M.F. Yassin, Impact of height and shape of building roof on air quality in urban street canyons, Atmospheric Environment 45 (29) (2011) 5220-5229.

[21] X. Xie, Z. Huang, J. Wang, The impact of urban street layout on local atmospheric environment, Building and Environment 41 (10) (2006) 1352-1363.

[22] N. Koutsourakis, P. Neofytou, A.G. Venetsanos, J.G. Bartzis, Parametric study of the dispersion aspects in a street-canyon area, International Journal of Environment and Pollution 25 (1-4) (2005) 155163.

[23] A. Kovar-Panskus, L. Moulinneuf, E. Savory, A. Abdelqari, J.F. Sini, J.M. Rosant, A wind tunnel investigation of the influence of solar-induced wall-heating on the flow regime within a simulated urban street canyon, Water, Air, and Soil Pollution 2 (5) (2002) 555-71.

[24] X. Xie, C.H. Liu, D.Y.C. Leung, Impact of building facades and ground heating on wind flow and pollutant transport in street canyons, Atmospheric Environment 41 (39) (2007) 9030-9049.

[25] Acceptable Thermal Environment for General Comfort based on ASHRAE Standard 55 (2013). https://www.ashrae.org

[26] L. Chen, E. Ng, Outdoor thermal comfort and outdoor activities: A review of research in the past decade, Cities 29 (2012) 118-125.

[27] S. Achour-Younsia, F. Kharratb, Outdoor thermal comfort: Impact of the geometry of an urban street canyon in a Mediterranean subtropical climate - Case study Tunis, Tunisia, Procedia - Social and Behavioral Sciences 216 (1) (2015) 689 - 700.

[28] M.K. Singh, S. Mahapatra, J. Teller, Development of thermal comfort models for various climatic zones of North-East India, Sustainable Cities and Society 14 (1) (2015) 133-145. 
[29] F. Ali-Toudert, H. Mayer, Numerical study on the effects of aspect ratio and orientation of an urban street canyon on outdoor thermal comfort in hot and dry climate, Building and Environment 41 (2006) 94-108.

[30] M. Santamouris, Cooling the cities - A review of reflective and green roof mitigation technologies to fight heat island and improve comfort in urban environments, Solar Energy 103 (1) (2014) 682-703.

[31] H. Akbari, L. Rose, Urban Surfaces and Heat Island Mitigation Potentials, Journal of the HumanEnvironmental System 11 (2) (2008) 85-101.

[32] H. Akbari, M. Pomerantz, H. Taha, Cool surfaces and shade trees to reduce energy use and improve air quality in urban areas, Solar Energy 70 (3) (2001) 295-310.

[33] H. Akbari, Measured energy savings from the application of reflective roofs in two small nonresidential buildings, Energy 28 (9) (2003) 953-967.

[34] H. Akbari, S. Konopacki, Energy effects of heat-island reduction strategies in Toronto, Canada, Energy 29 (2) (2004) 191-210.

[35] D. Kolokotsa, M. Santamouris, S.C. Zerefos, Green and cool roofs' urban heat island mitigation potential in European climates for office buildings under free floating conditions, Solar Energy 95 (1) (2013) 118-130.

[36] J. Kim, E. Pardyjak, D.Y. Kim, K.S. Han, B.H. Kwon, Effects of Building-Roof Cooling on Flow and Air Temperature in Urban Street Canyons, Asia-Pacific Journal of Atmospheric Sciences 50 (3) (2014) 365-375.

[37] J. Kim, Numerical Study on the Effects of Building-Roof Cooling in Urban Street Canyons, American Geophysical Union, Fall Meeting (2013) 43-193.

[38] K. Uehara, S. Murakami, S. Oikawa, S. Wakamatsu, Wind tunnel experiments on how thermal stratification affects flow in and above urban street canyons, Atmospheric Environment 34 (10) (2000) $1553-1562$.

[39] S. Ghani, E.M.A.A. ElBialy, F. Bakochristou, S.M.A. Gamaledin, M.M. Rashwan, The effect of forced convection and PCM on helmets' thermal performance in hot and arid environments, Applied Thermal Engineering 111 (2017) 624-637.

[40] Architecture Design Handbook;

http://www.copper.org/applications/architecture/arch_dhb/arch-details/domes_spires_vaults/

[41] T.R. Oke, Street design and urban canopy layer climate, Energy and Building 11 (1-3) (1988) 103113.

[42] D.N. Asimakopoulos, V.D. Assimakopoulos, N. Chrisomallidou, Energy and Climate in the Urban Built Environment, James \& James, London, UK, 2001.

[43] J.A. Voogt, T.R. Oke, Thermal Remote Sensing of Urban Areas. Remote Sensing of Environment (Special issue on Urban Areas), (2003) 370-384.

[44] C. Rosenzweig, W. Solecki, Mitigating New York City's heat island with urban forestry, living roofs, and light surfaces. Nasa Publication, 2006.

[45] A. de Lieto Vollaro, G. de Simone, R. Romagnoli, A. Vallati, S. Botillo, Numerical Study of Urban Canyon Microclimate Related to Geometrical Parameters, Sustainability (ISSN) 6 (11) (2014) 7894-7905. 
[46] W. Pasut, M. De Carli, Evaluation of various CFD modelling strategies in predicting airflow and temperature in a naturally ventilated double skin façade, Applied Thermal Engineering 37 (2012) 267274.

[47] J.J. Baik, Y.S. Kang, J.J. Kim, Modeling reactive pollutant dispersion in an urban street canyon, Atmospheric Environment 41 (5) (2007) 934-949.

[48] FLUENT Inc., FLUENT 6.3.26 user Manual (2010).

[49] J.V. Boussinesq, Théorie de l'écoulement tourbillonnant et tumultueux des liquides dans les lits rectilignes a grande section. Paris, Gauthier-Villars et fils 1, 1842-1929 (Retrieved 10 October 2015). 94p.

[50] M. Nikolopoulou, N. Baker, K. Steemers, Thermal comfort in outdoor urban spaces: understanding the human parameter, Solar Energy 70 (3) (2001) 227-235.

[51] V. Cheng, E. Ng, C. Chan, B. Givoni, Outdoor thermal comfort study in sub-tropical climate: A longitudinal study based in Hong Kong, International Journal of Biometeorology 56 (1) (2012) 43-56.

[52] Acceptable Thermal Environment for General Comfort based on ASHRAE Standard 55 (2010). https://www.ashrae.org

[53] L. Zhao, X. Lee, R.B. Smith, K. Oleson, Strong contributions of local background climate to urban heat islands. Nature 511 (2014) 216-219.

[54] A.P. Gagge, J.A.J. Stolwijk, Y. Nishi, An effective temperature scale based on a simple model of human physiological regulatory response, ASHRAE Transactions 77 (1) (1971) 247-257.

[55] B. Blocken, T. Stathopoulos, J. Carmeliet, CFD simulation of the atmospheric boundary layer: wall function problems, Atmospheric Environment, 41 (2) (2007) 238-252.

[56] S. Magnusson, A. Dallman, D. Entekhabi, R. Britter, H.J.S. Fernando, L. Norford, On thermally forced flows in urban street canyons, Environmental Fluid Mechanics 14 (6) (2014) 1427-1441.

[57] B. Wang, G. Cui, Large Eddy Simulation of Unstably Stratified Turbulent Flow over Urban-Like Building Arrays, Journal of Applied Mathematics (2013) 10 p.

[58] International Organization for Standardization (ISO), ISO 7730 - Moderate thermal environments determination of the PMV and PPD indices and specification of the conditions for thermal comfort (1994). 


\section{Captions}

Fig. 1. Computational urban street canyon configurations and domain. (a) Sketch of the roof-shaped model, (b) Schematic diagram of the computational domain and boundary conditions.

Fig. 2. Vertical profiles of measured and simulated (a) temperature and (b) horizontal flow speed. The temperature is normalized by $\left(\Theta-\Theta_{\mathrm{a}}\right) /\left(\Theta_{\mathrm{f}}-\Theta_{\mathrm{a}}\right)$ and the horizontal flow speed is normalized by $\mathrm{u} / \mathrm{U}$.

Fig. 3. Study of the aerodynamic parameters in street canyons with aspect ratio 0.5 , rise / run ratio zero, 12 and domed roof in isothermal condition. (a) structure of the flow field, (b) distribution of the turbulent kinetic energy $\left(\mathrm{m}^{2} / \mathrm{s}^{2}\right)$ and (c) spatial contours of normalized pollutant concentration $\left(\mathrm{Kmol} / \mathrm{m}^{3}\right)$.

Fig. 4. Study of the aerodynamic parameters in street canyons with aspect ratio 1.0, rise / run ratio zero, 12 and domed roof in isothermal condition. (a) structure of the flow field, (b) distribution of the turbulent kinetic energy and (c) spatial contours of normalized pollutant concentration.

Fig. 5. Study of the aerodynamic parameters in street canyons with aspect ratio 2.0, rise / run ratio zero, 12 and domed roof in isothermal condition. (a) structure of the flow field, (b) distribution of the turbulent kinetic energy and (c) spatial contours of normalized pollutant concentration.

Fig. 6. The profiles of velocity magnitude in center-line for different models of street canyons with aspect ratio 0.5 (a), 1.0 (b) and 2.0 (c), in isothermal condition.

Fig. 7. The comparison of airflow velocity profile in street canyons with aspect ratio 0.5 , for isothermal and non-isothermal condition in central region.

Fig. 8. Study of the aerodynamic parameters in street canyons with aspect ratio 0.5 , rise / run ratio zero, 12 and domed roof in non-isothermal condition. (a) structure of the flow field, (b) distribution of the turbulent kinetic energy and (c) spatial contours of normalized pollutant concentration.

Fig. 9. The comparison of airflow velocity profile in street canyons with aspect ratio 1.0, for isothermal and non-isothermal condition in central region.

Fig. 10. Study of the aerodynamic parameters in street canyons with aspect ratio 1.0, rise / run ratio zero, 12 and domed roof in non-isothermal condition. (a) structure of the flow field, (b) distribution of the turbulent kinetic energy and (c) spatial contours of normalized pollutant concentration.

Fig. 11. The comparison of airflow velocity profile in street canyons with aspect ratio 2.0, for isothermal and non-isothermal condition in central region.

Fig. 12. Study of the aerodynamic parameters in street canyons with aspect ratio 2.0, rise / run ratio zero, 12 and domed roof in non-isothermal condition. (a) structure of the flow field, (b) distribution of the turbulent kinetic energy and (c) spatial contours of normalized pollutant concentration.

Fig. 13. Spatial contours of temperature in street canyon with different roof shaped in aspect ratio 1.0 for non-isothermal condition. (a) gabled roof (slope=0), (b) gabled roof (slope=3), (c) gabled roof (slope=6), (d) gabled roof (slope=9), (e) gabled roof (slope=12) and (f) domed roof.

Fig. 14. The profiles of temperature in center-line for different models of street canyons with aspect ratio 1.0 in non-isothermal condition. (a) leeward region, (b) center region and (c) windward region.

Fig. 15. PMV index in street canyons with aspect ratio of 1.0 for non-isothermal condition (a): (a-1) leeward region, (a-2) central region, and (a-3) windward region. And PPD index in street canyons with different aspect ratios for non-isothermal condition center areas (b): (b-1) H/W=0.5, (b-2) H/W=1.0, and (b-3) $\mathrm{H} / \mathrm{W}=2.0$. 
Table. 1. Computational parameters employed in the CFD calculations.

Table. 2. Specifications of materials used for solid surfaces [45].

Table. 1. Computational parameters employed in the CFD calculations.

\begin{tabular}{ccc}
\hline Aspect ratio H/W & No. of cells & No. of nodes \\
\hline 0.5 & 349,788 & 351,896 \\
1 & 223,900 & 225,558 \\
2 & 440,274 & 442,582 \\
\hline
\end{tabular}

Table. 2. Specifications of materials used for solid surfaces [45].

\begin{tabular}{ccccc}
\hline row & surfaces & $\begin{array}{c}\text { density } \\
\left(\mathrm{kg} / \mathrm{m}^{3}\right)\end{array}$ & $\begin{array}{c}\text { specific heat } \\
(\mathrm{j} / \mathrm{kg} \cdot \mathrm{K})\end{array}$ & $\begin{array}{c}\text { thermal conductivity } \\
(\mathrm{w} / \mathrm{m} \cdot \mathrm{K})\end{array}$ \\
\hline 1 & ground & 1000 & 1000 & 2 \\
2 & windward, leeward, roof & 1000 & 1000 & 0.15 \\
\hline
\end{tabular}


a)

\begin{tabular}{c|c|c|c|c|c|c} 
Slope & $\mathbf{0}$ & $\mathbf{3}$ & $\mathbf{6}$ & $\mathbf{9}$ & $\mathbf{1 2}$ & Dome \\
\hline Roof Shape & $\square \square \square$ & $\square \Omega \Omega$ & $\Omega \Omega \Omega$ & $\Omega$ & $\Omega$
\end{tabular}

Height/Width $=0.5$

Height $/$ Width $=1.0$

wind speed $=0.3 \mathrm{~m} / \mathrm{s}$

1) $($ Rise/Run $) / 12=0$
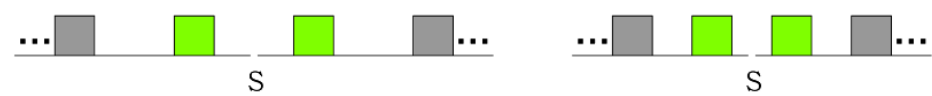

Height $/$ Width $=2.0$

2) $($ Rise/Run $) / 12=3$
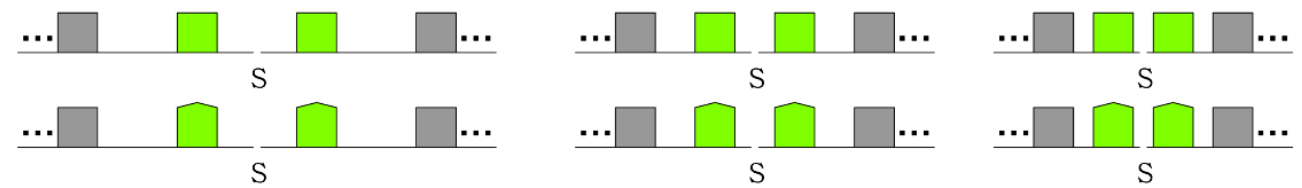

2) (Rise/Run)/12= 3
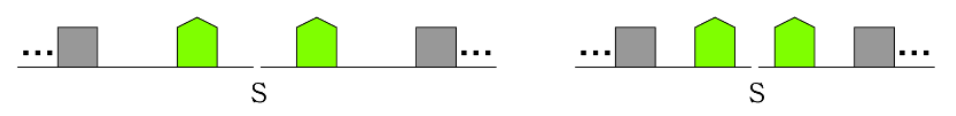

3) $($ Rise/Run $) / 12=6$

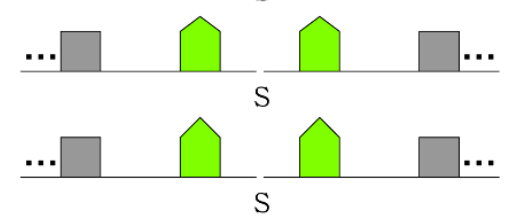

4) $($ Rise/Run $) / 12=9$
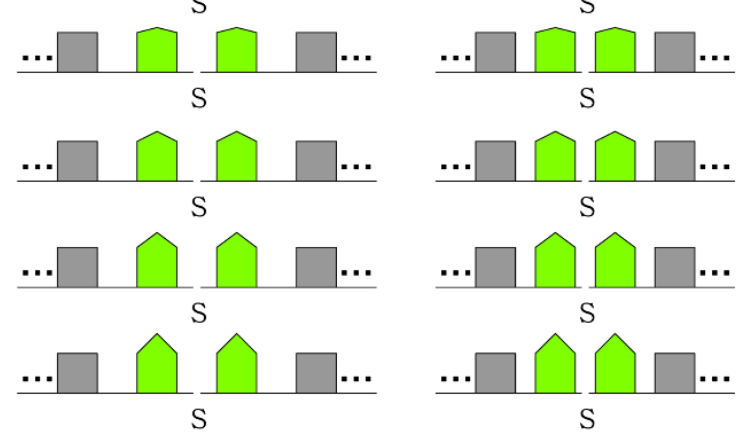

5) $($ Rise/Run $) / 12=12$

6) Dome Roof
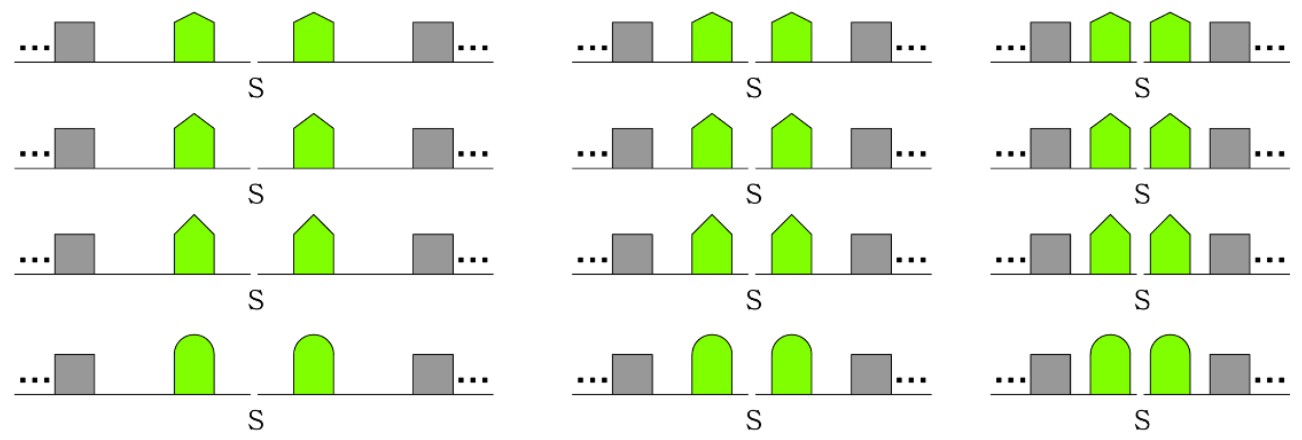

\section{b)}

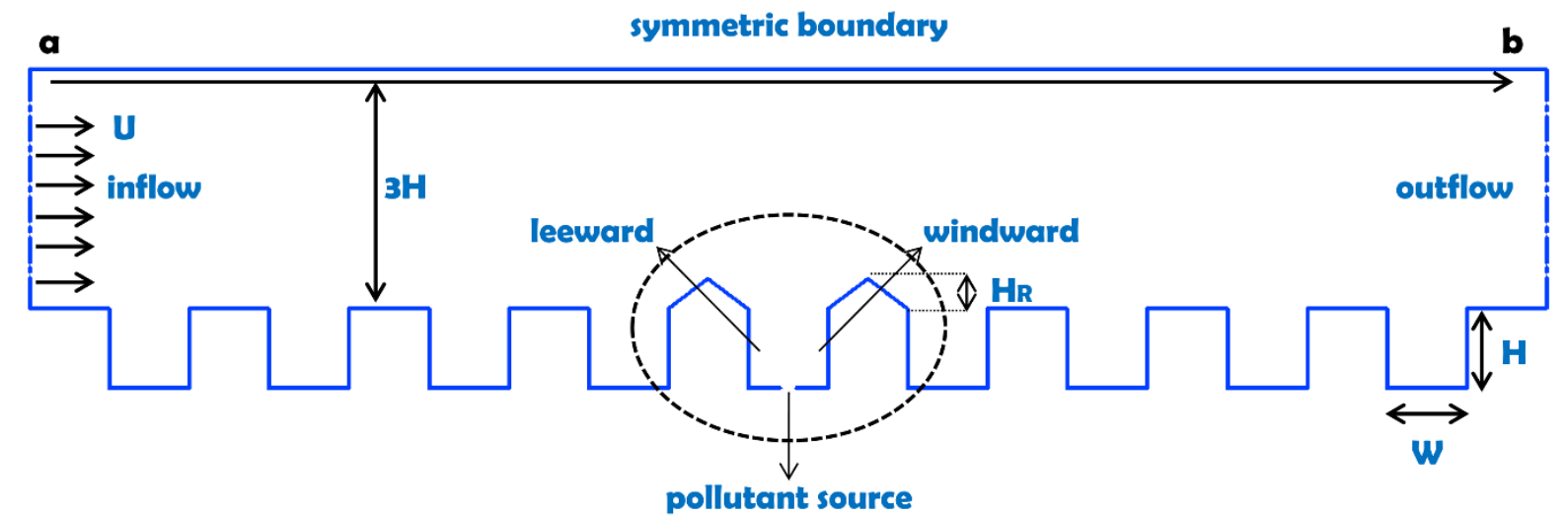

Figure 1 

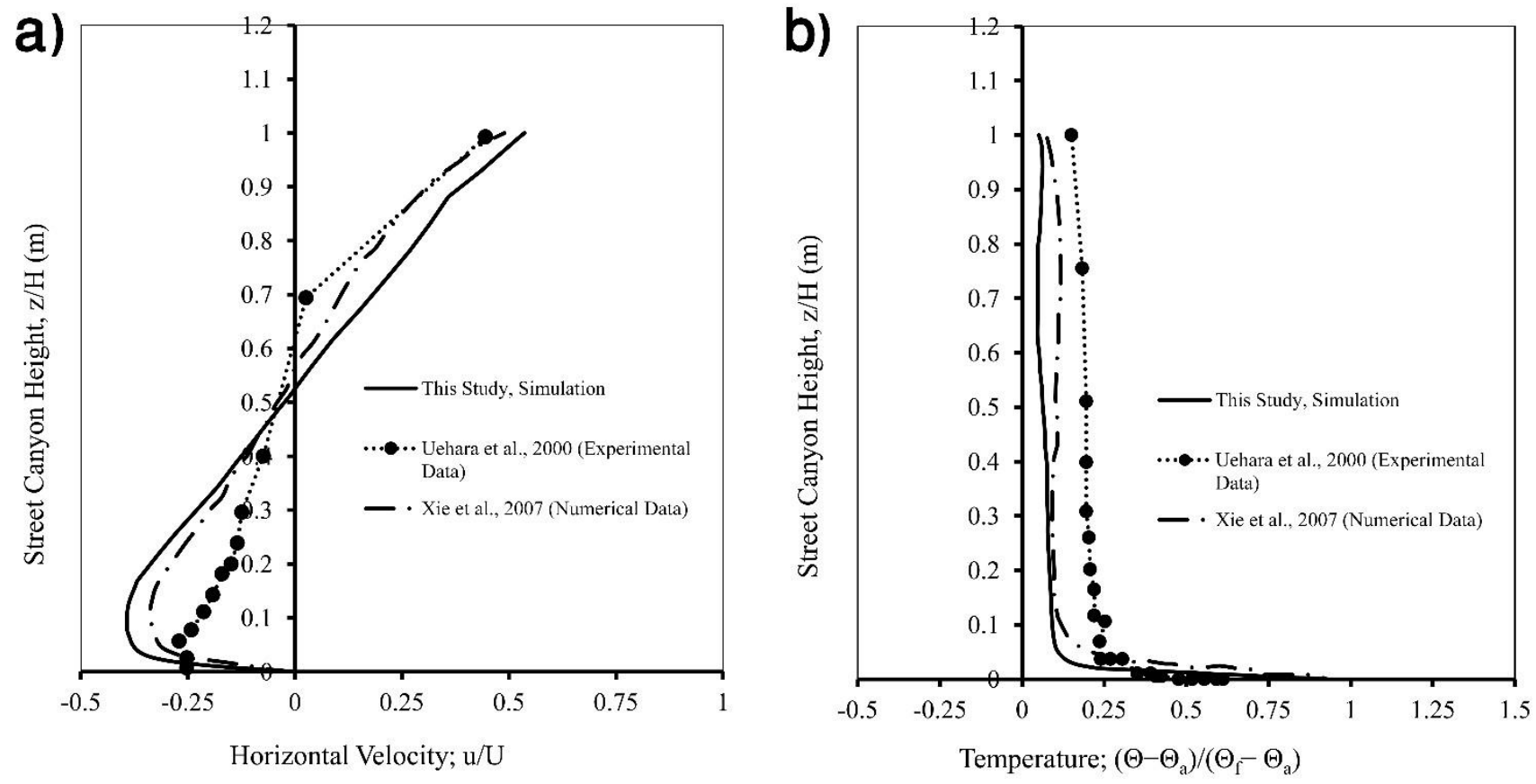

Figure 2 

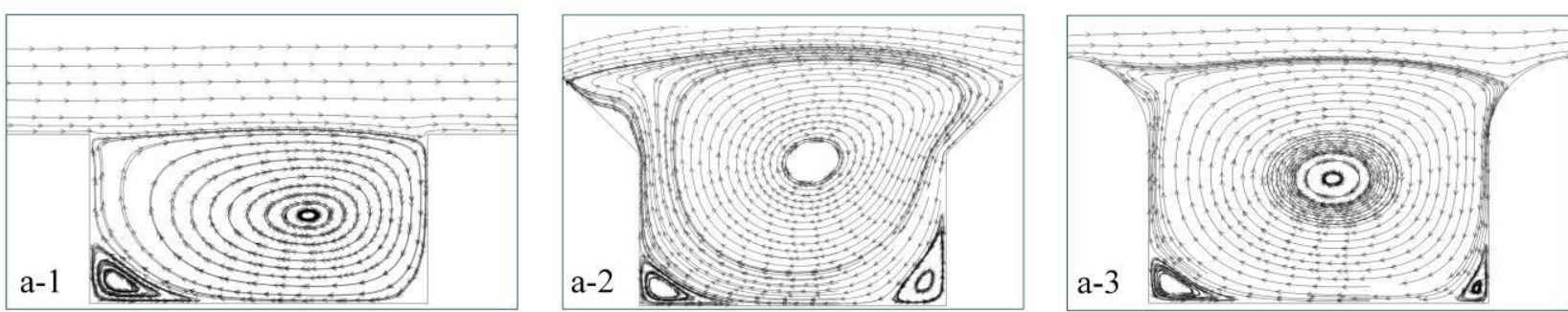

(a)
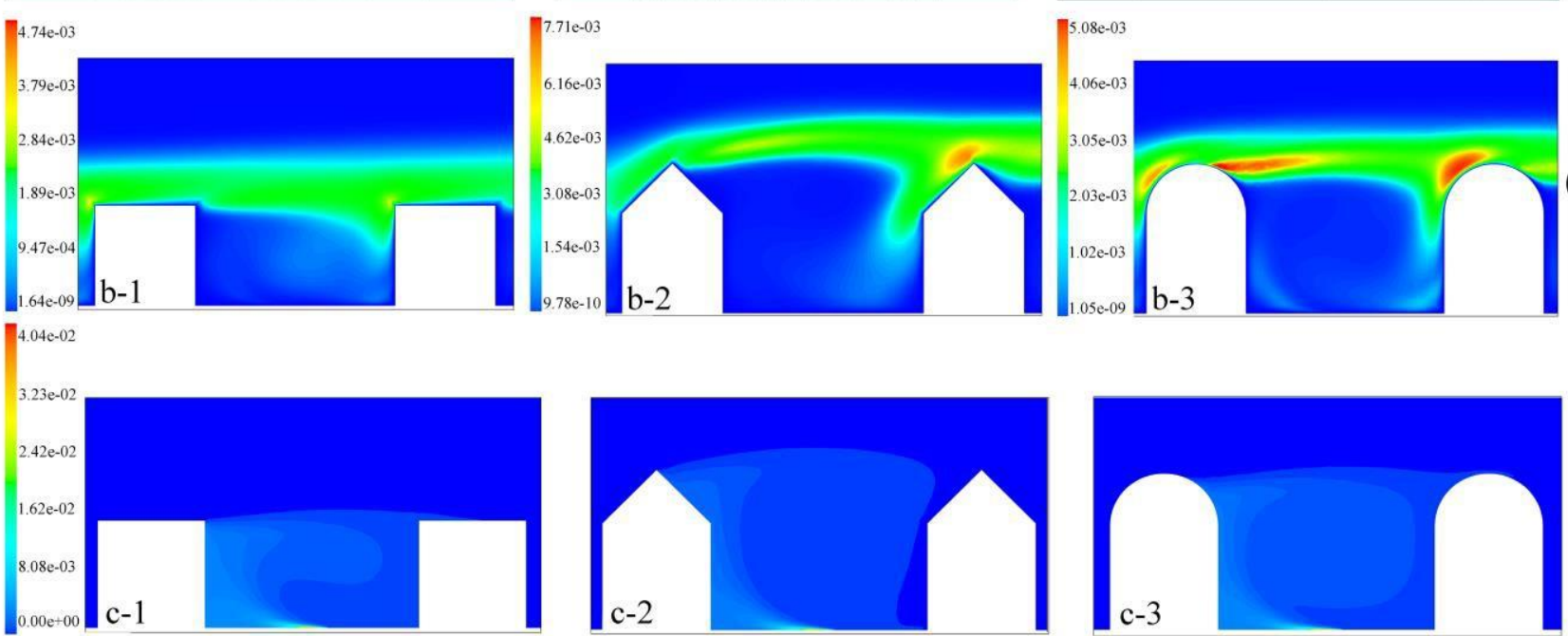

(c)

Figure 3 

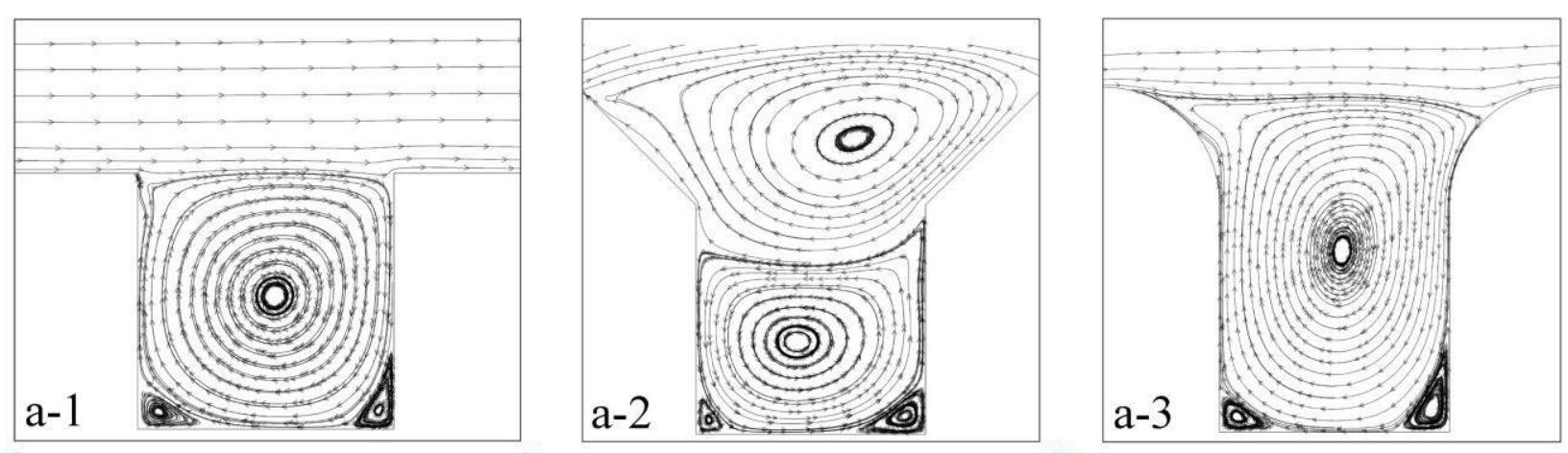

(a)
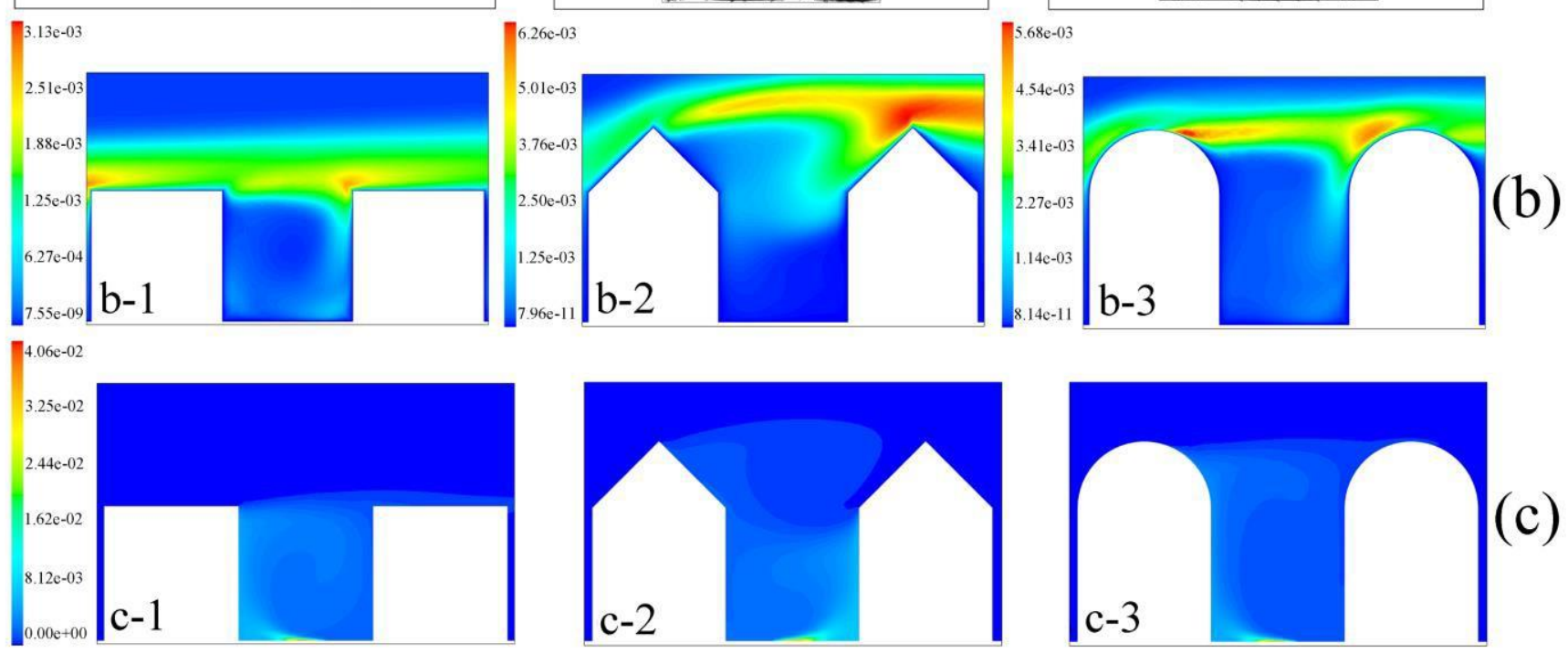

Figure 4 

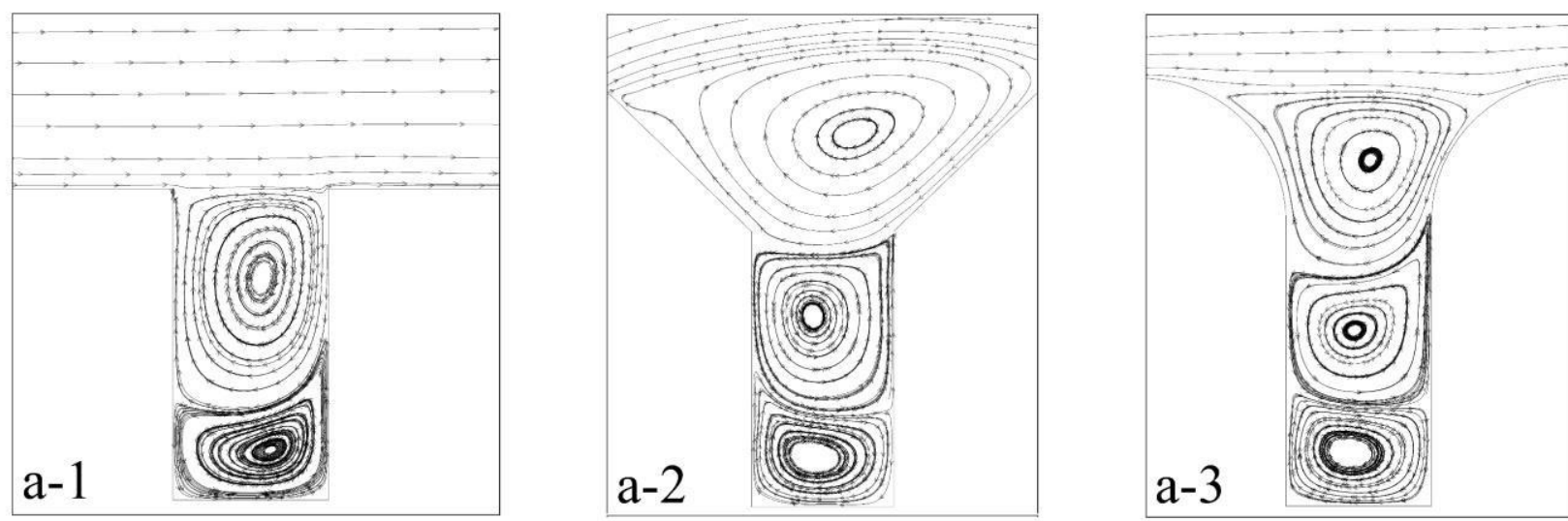

(a)
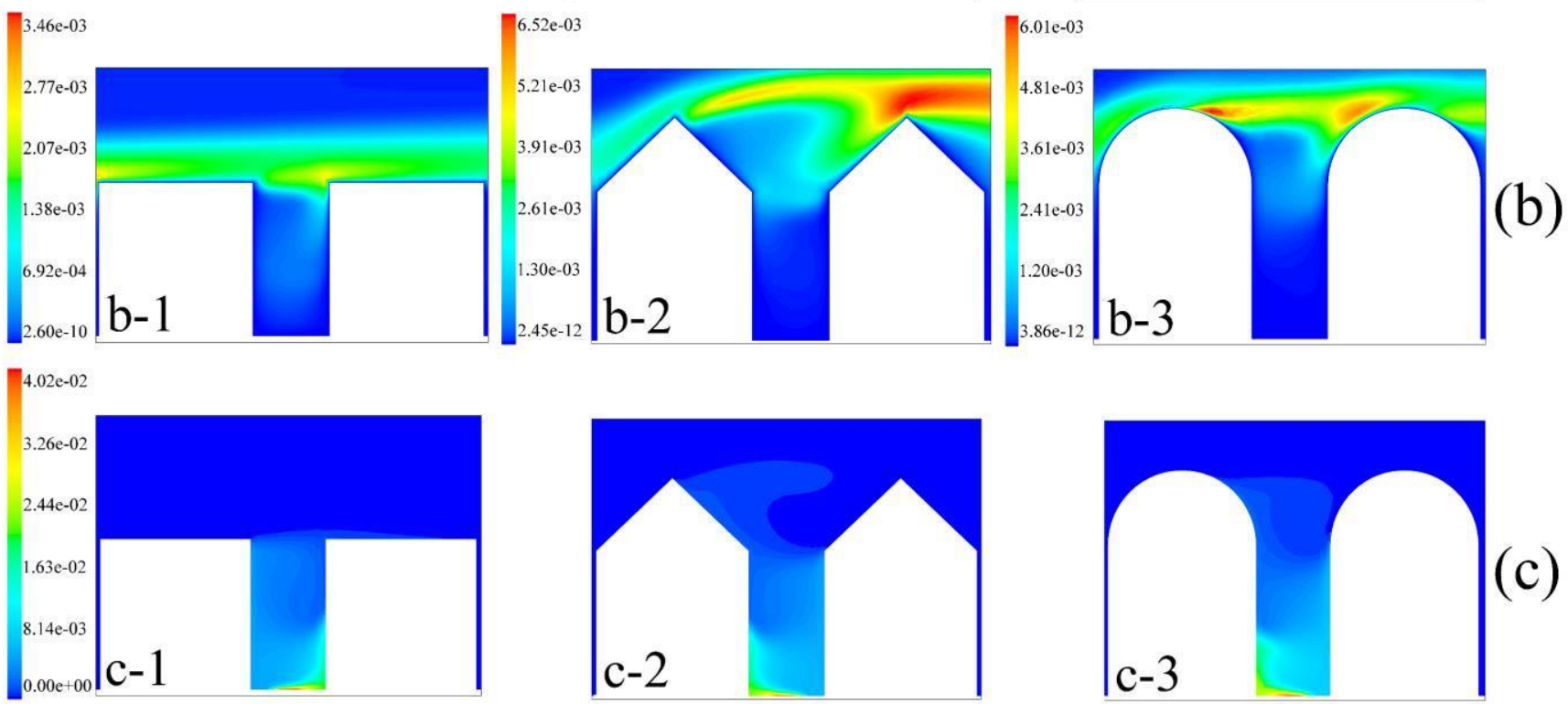

(c)

Figure 5 

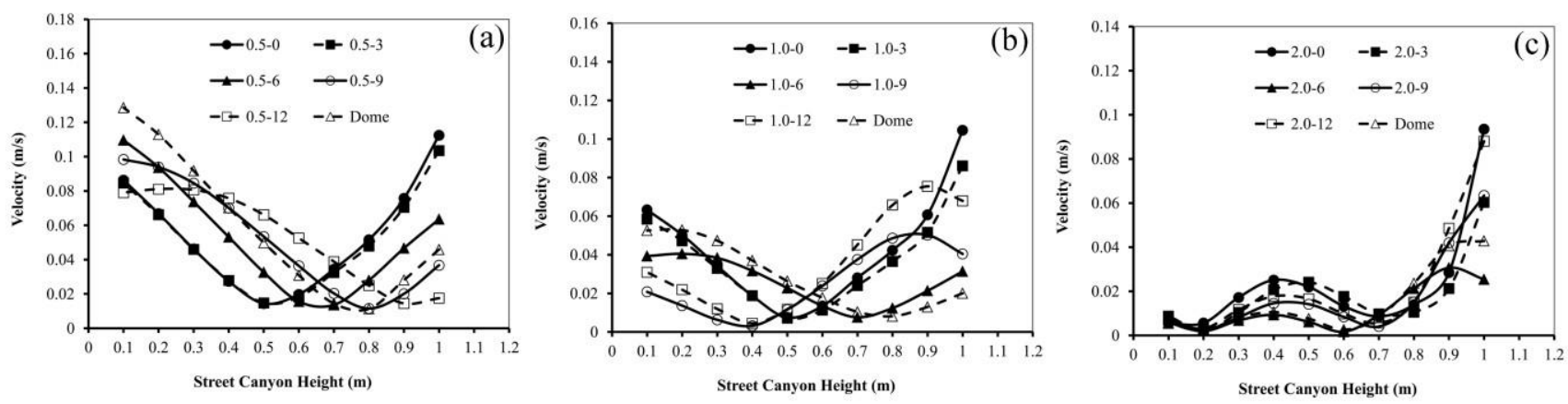

Figure 6 

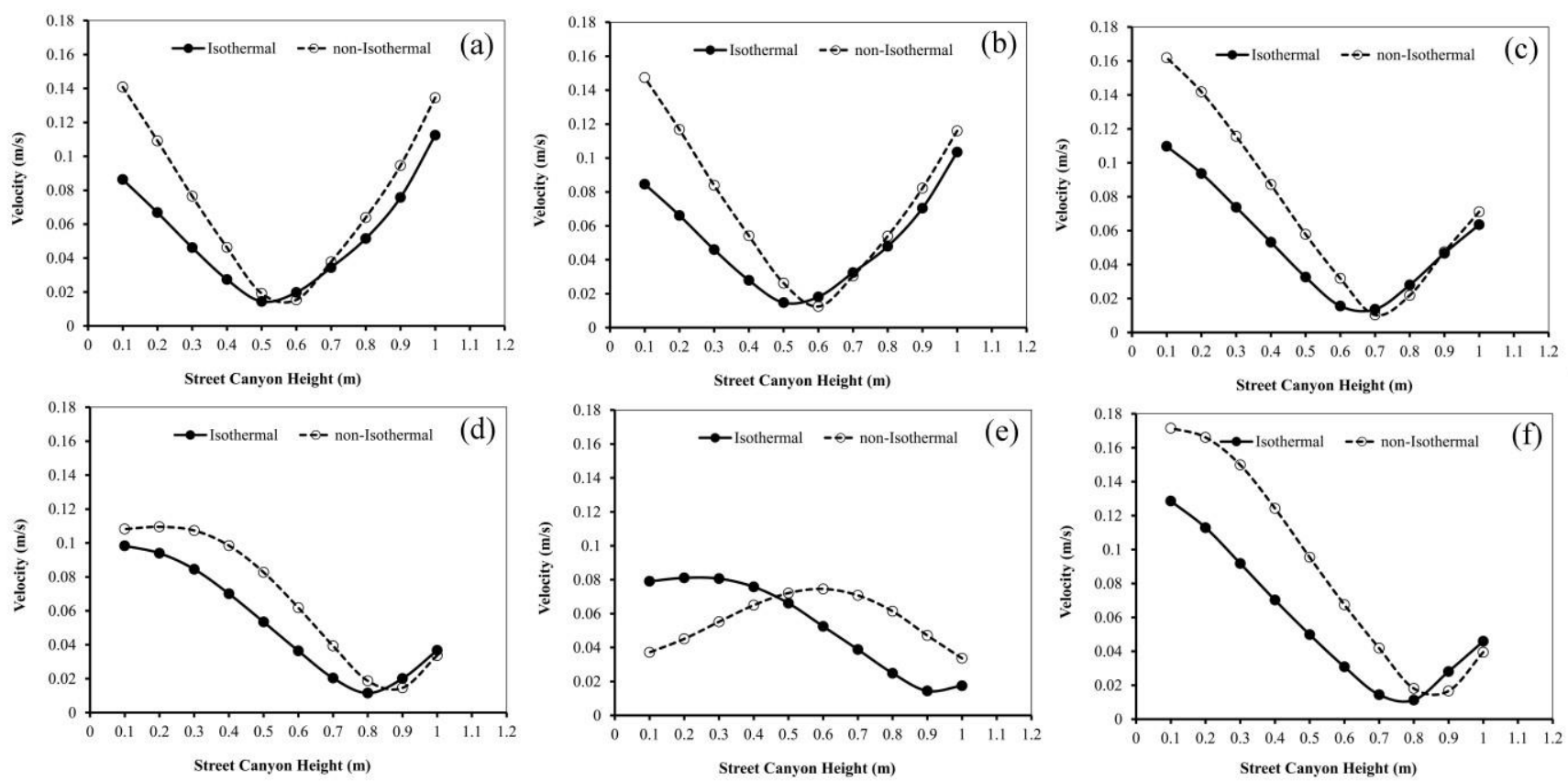

Figure 7 

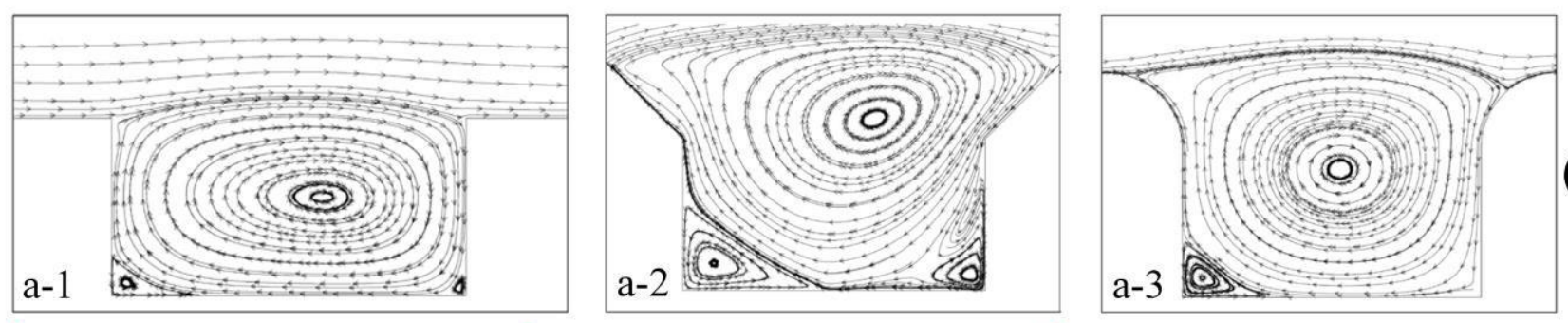

(a)
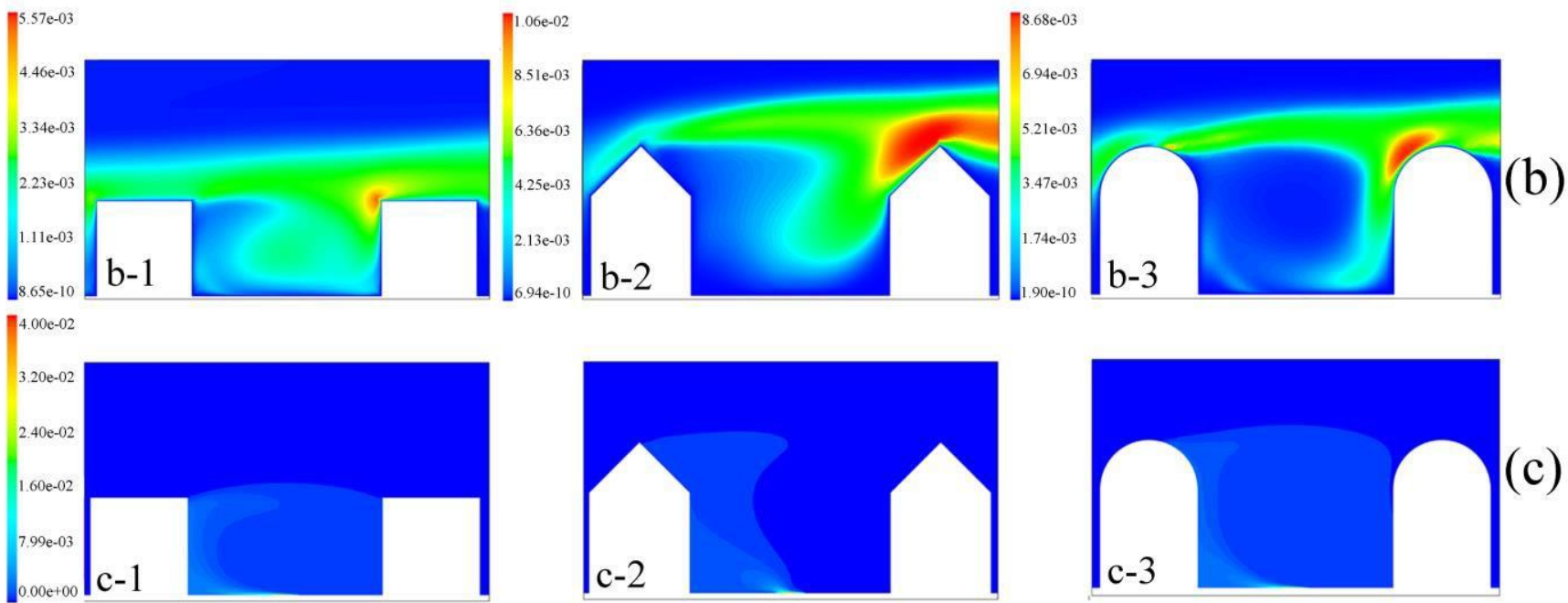

Figure 8 

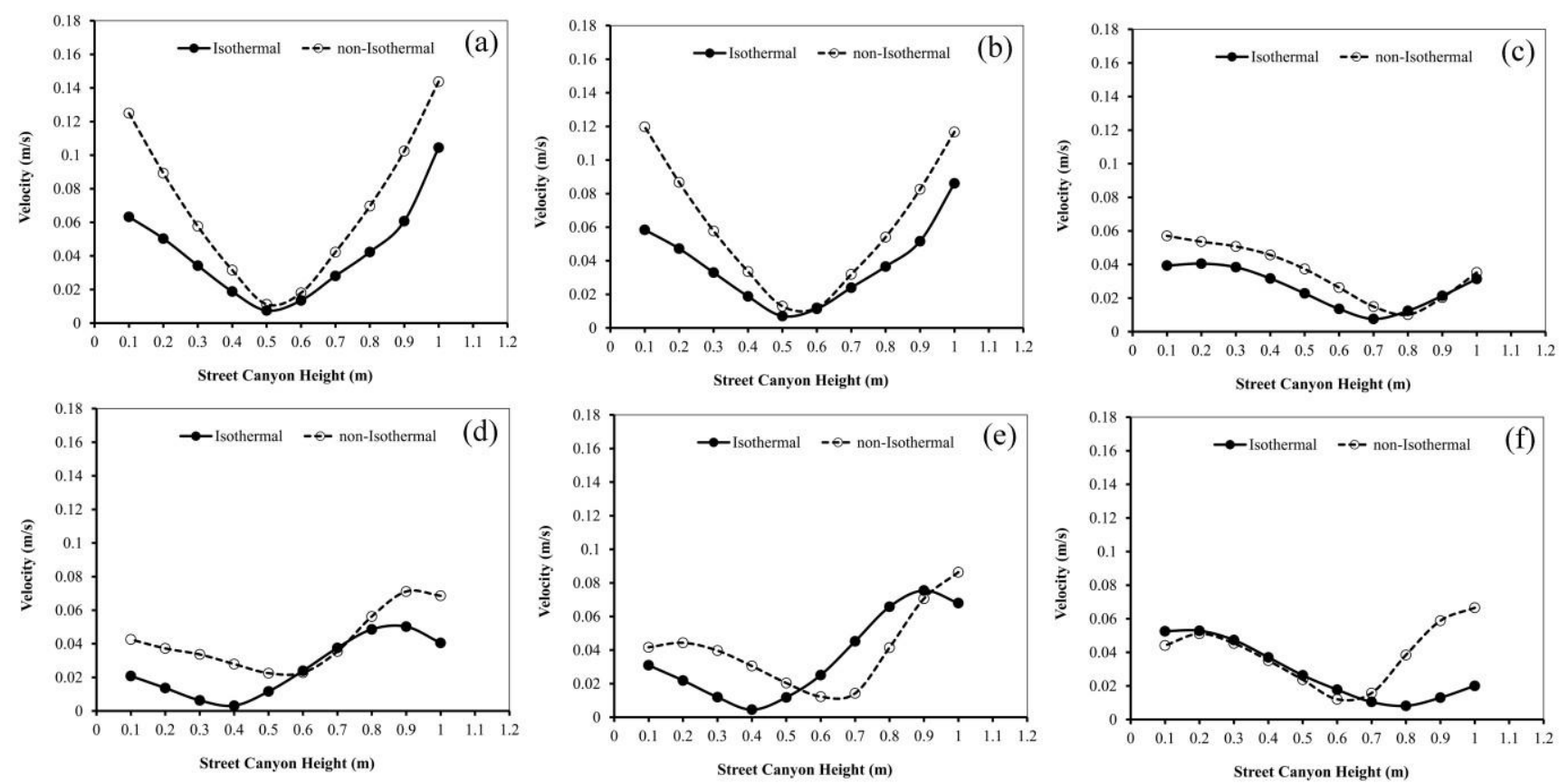

Figure 9 

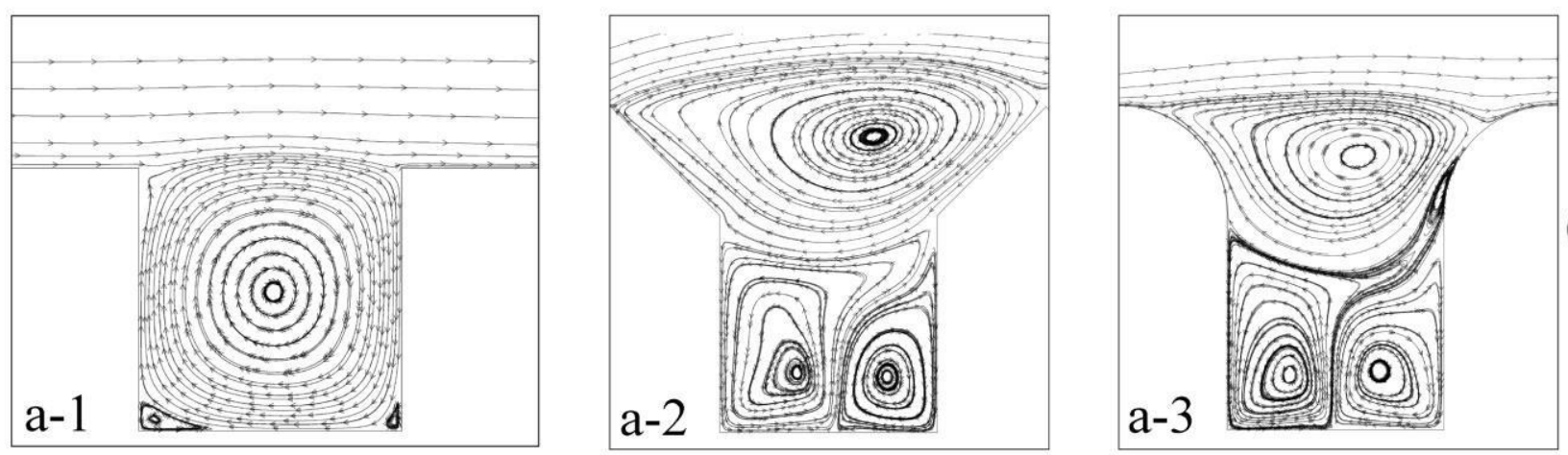

(a)
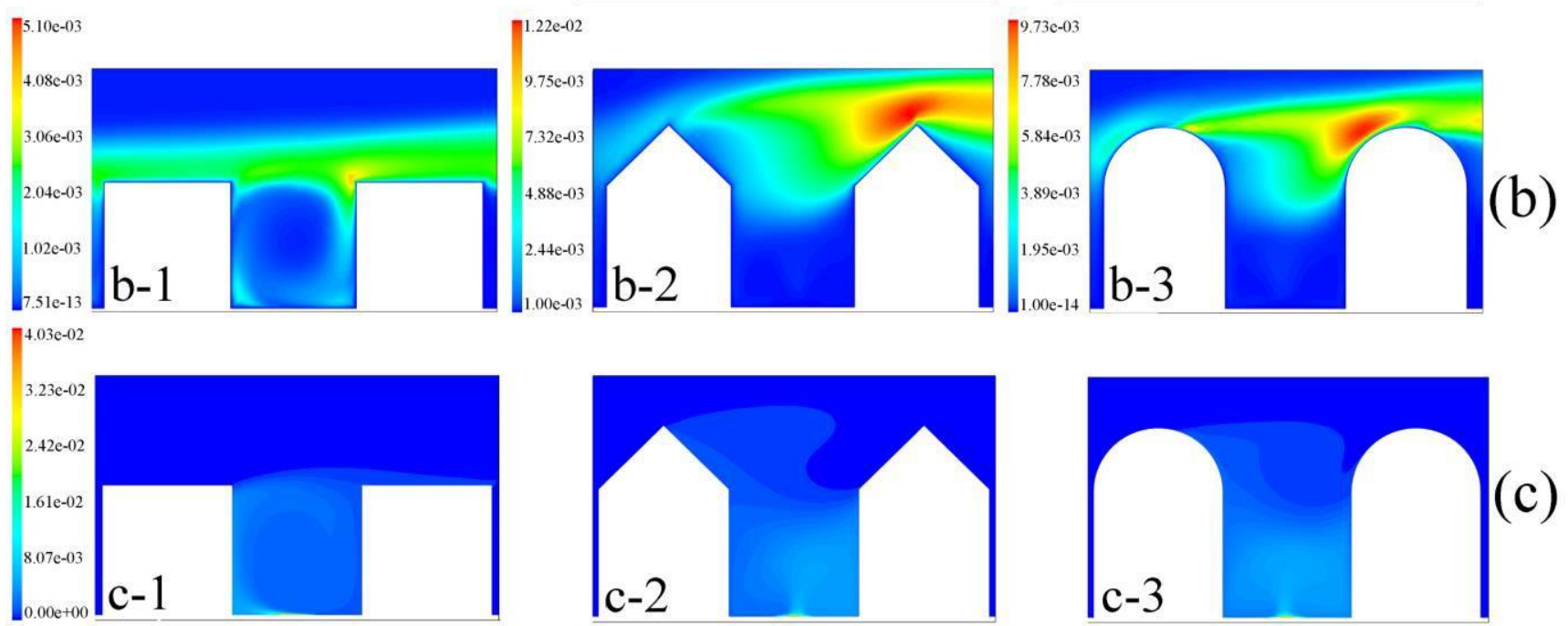

Figure 10 

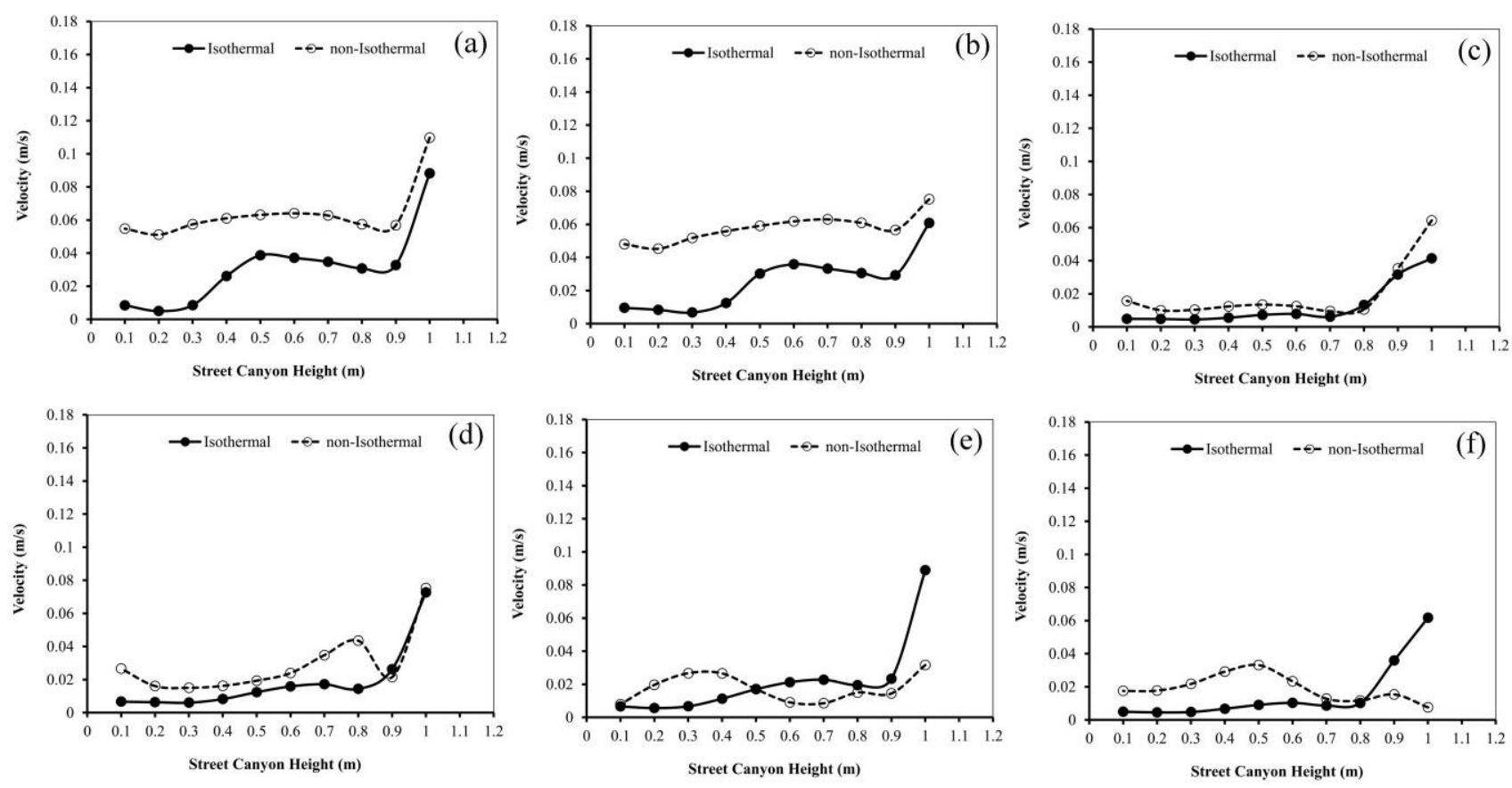

Figure 11 

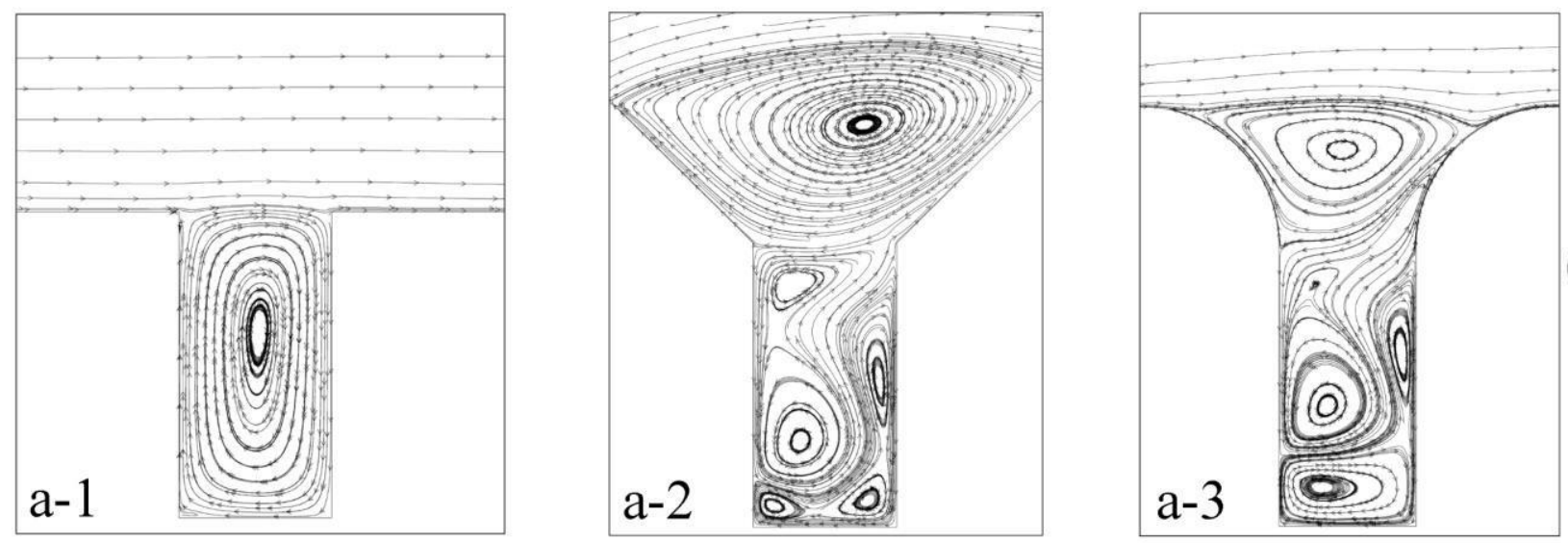

(a)
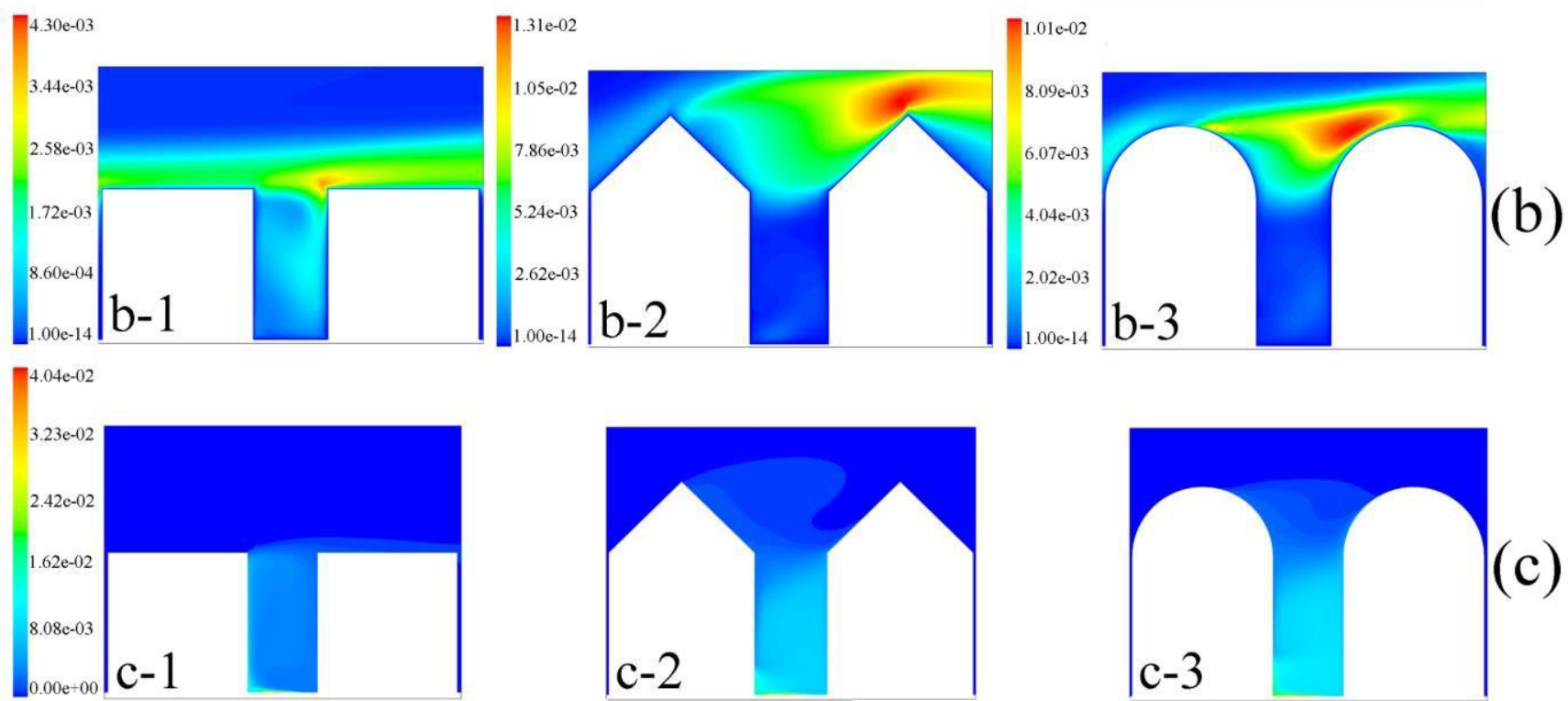

Figure 12 

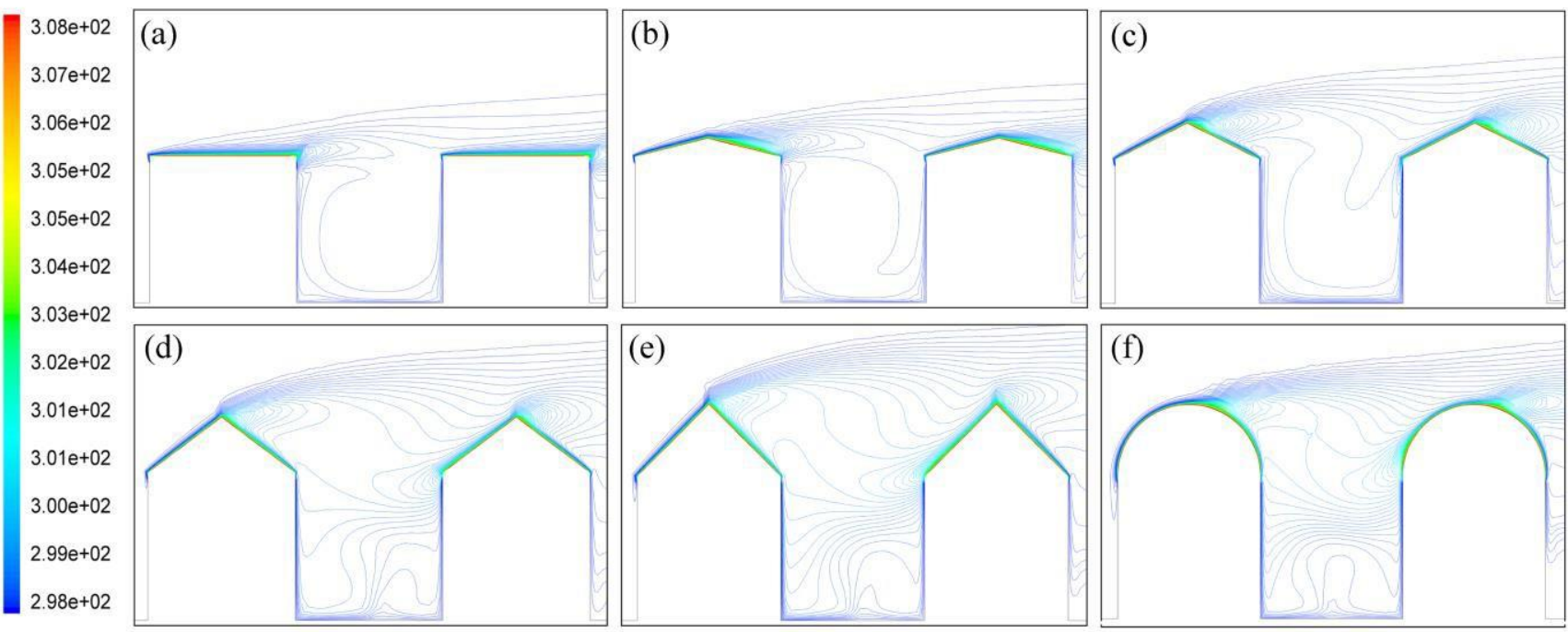

Figure 13 

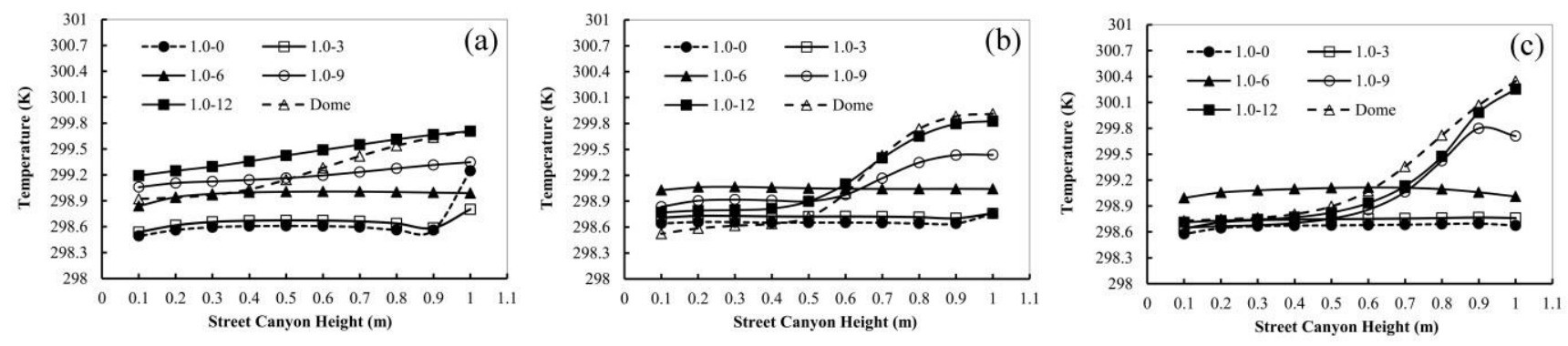

Figure 14 


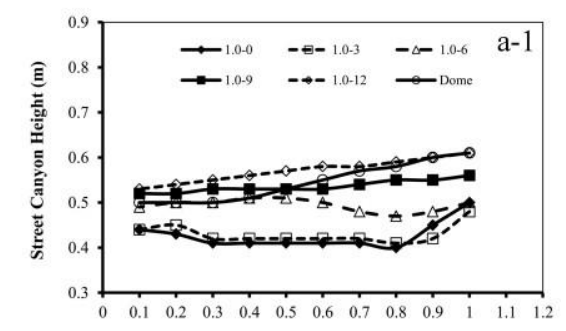

PMV Factor

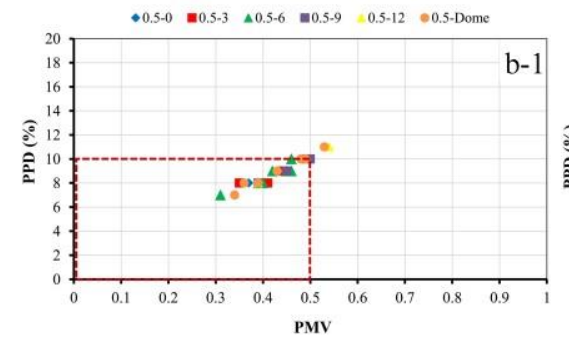

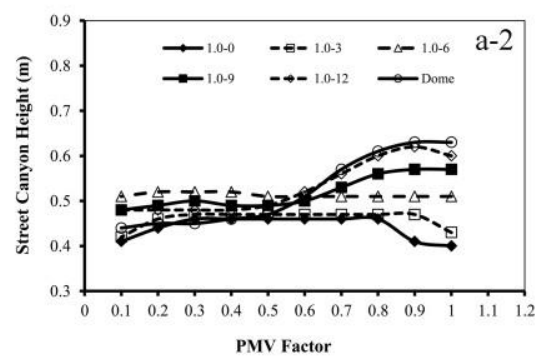
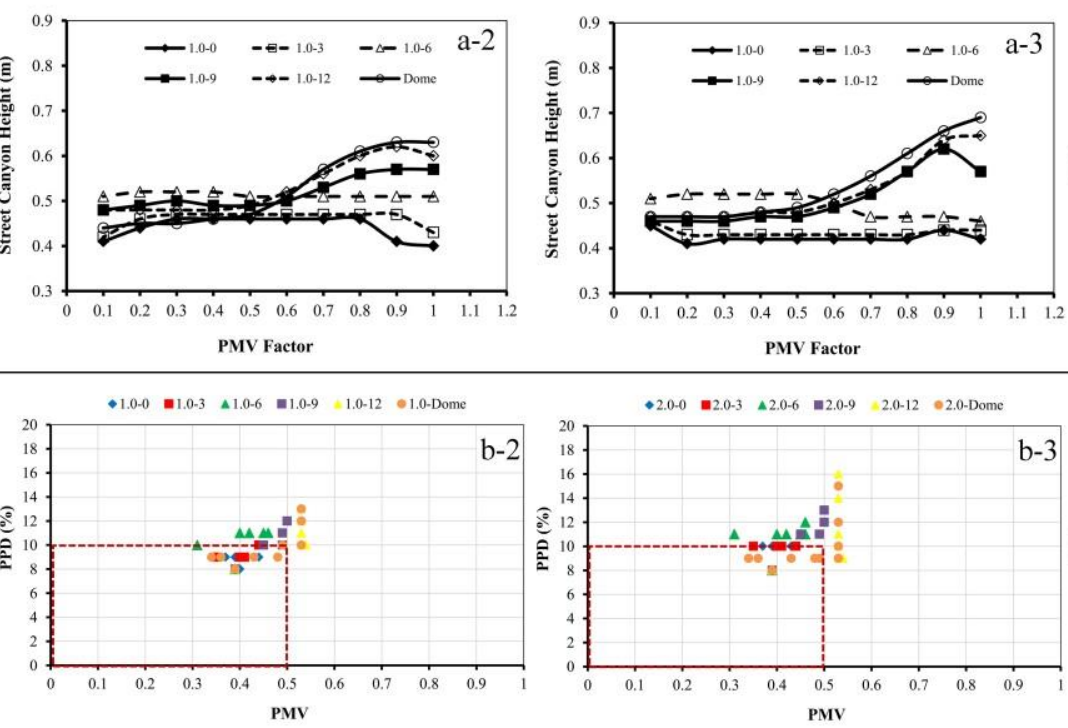

Figure 15 (a)

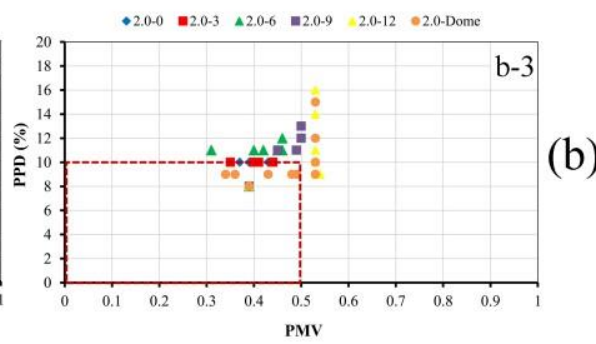

(b) 